\title{
Leaf trait plasticity alters competitive ability and functioning of simulated tropical trees in response to elevated carbon dioxide
}

\author{
Marlies Kovenock ${ }^{1}$, Charles D. Koven ${ }^{2}$, Ryan G. Knox $^{2}$, Rosie A. Fisher ${ }^{3,4}$, \& \\ Abigail L.S. Swann ${ }^{5,1}$
${ }^{1}$ Department of Biology, University of Washington, Seattle, WA
${ }^{2}$ Climate and Ecosystem Sciences Division, Lawrence Berkeley National Laboratory, Berkeley, CA ${ }^{3}$ National Center for Atmospheric Research, Boulder, CO \\ ${ }^{4}$ Centre Européen de Recherche et de Formation Avancée en Calcul Scientifique (CERFACS), Toulouse, \\ France \\ ${ }^{5}$ Department of Atmospheric Sciences, University of Washington, Seattle, WA
}

\section{Key Points:}

- Including the observed response of leaf traits to higher $\mathrm{CO}_{2}$ results in lower competitive ability for modeled tropical trees

- Concurrent changes in multiple leaf traits could help maintain per-area photosynthetic rates and confer a competitive advantage

- Resulting ecosystem-scale carbon uptake depends on the magnitude of trait plasticity coupled with changes in plant type abundance 


\begin{abstract}
The response of tropical ecosystems to elevated carbon dioxide $\left(\mathrm{CO}_{2}\right)$ remains a critical uncertainty in projections of future climate. Here we investigate how leaf trait plasticity in response to elevated $\mathrm{CO}_{2}$ alters projections of tropical forest competitive dynamics and functioning. We use vegetation demographic model simulations to quantify how plasticity in leaf mass per area and leaf carbon to nitrogen ratio alter the responses of carbon uptake, evapotranspiration, and competitive ability to a doubling of $\mathrm{CO}_{2}$ in a tropical forest. Observationally constrained leaf trait plasticity in response to $\mathrm{CO}_{2}$ fertilization reduces the degree to which tropical tree carbon uptake is affected by a doubling of $\mathrm{CO}_{2}$ (up to $-14.7 \%$ as compared to a case with no plasticity; $95 \%$ confidence interval $C I_{95 \%}-14.4$ to -15.0 ). It also diminishes evapotranspiration (up to $-7.0 \%, C I_{95 \%}$ -6.4 to -7.7 ), and lowers competitive ability in comparison to a tree with no plasticity. Consideration of leaf trait plasticity to elevated $\mathrm{CO}_{2}$ lowers tropical ecosystem carbon uptake and evapotranspirative cooling in the absence of changes in plant type abundance. However, 'plastic' responses to high $\mathrm{CO}_{2}$ which maintain higher levels of plant productivity are potentially more competitively advantageous, thus, including changes in plant type abundance may mitigate these decreases in ecosystem functioning. Models that explicitly represent competition between plants with alternative leaf trait plasticity in response to elevated $\mathrm{CO}_{2}$ are needed to capture these influences on tropical forest functioning and large-scale climate.
\end{abstract}

\title{
Plain Language Summary
}

When tropical trees grown in air with a high concentrations of carbon dioxide it has been observed that they grow leaves and change aspects of how leaves work, called leaf traits. We used computer simulations to look at how changes in two particular leaf traits, leaf thickness and the concentration of nitrogen in leaves, alter how much tropical trees grow when carbon dioxide concentrations are high. We find that trees grow less when they have lower concentrations of nitrogen in leaves, but that if they can simultaneously make their leaves thicker this alleviates the negative effects. This holds true both when plants are growing without any competition, and also corresponds to how likely they are to grow better than a neighbor with a different combination of leaf traits. Our findings suggest that if tropical trees change only the concentration of nitrogen in their leaves then tree growth and the related transfer of carbon into the land and water back to the atmosphere will be reduced. However if the two trait changes occur simultaneously tropical forests could maintain exchanges of carbon and water close to the rates at which they currently occur.

\section{Introduction}

Tropical forests currently exert strong control over large-scale carbon, water, and energy fluxes and thus strongly influence global climate (Bonan, 2008; Davin \& de NobletDucoudré, 2010; Cusack et al., 2016; Cox et al., 2000). Yet, the poorly understood response of tropical ecosystems to elevated carbon dioxide $\left(\mathrm{CO}_{2}\right)$ over the coming decades and centuries remains a key uncertainty in projections of future climate (e.g., Ciais et al., 2013; Zhang et al., 2015; Lloyd \& Farquhar, 2008; Schimel et al., 2015; Brienen et al., 2015; Hickler et al., 2008; Fisher et al., 2010; Cernusak et al., 2013; Leakey, Bishop, \& Ainsworth, 2012; van der Sleen et al., 2015; Cusack et al., 2016). Predictive models of the carbon cycle are predicated on using observable plant properties (traits) as inputs to mechanistic models that project the functioning of ecosystems under unobserved future conditions. Typically, most plant traits are fixed in these models for a given plant functional type, irrespective of environmental conditions, although some newer approaches allow traits to vary based on optimality arguments (e.g. Caldararu et al., 2020). In reality, leaf traits vary both across plant types as well as within plant types across envi- 
ronmental gradients. Further, under experimental conditions, a number of leaf traits have demonstrated plasticity, in that the leaves of existing trees are altered in response to, for example, elevated $\mathrm{CO}_{2}$ concentrations (e.g., Garbutt et al., 1990; Yin, 2002; Verheijen et al., 2015). Alterations in leaf traits can modify plant photosynthesis and evapotranspiration rates. Thus this leaf trait plasticity could alter ecosystem functioning, with potential implications for large-scale climate. We use the term 'plasticity', rather than 'acclimation' to allow for the fact that these changes might occur as a result of nutrient scarcity, rather than a specific 'acclimation' to altered conditions. The capacity for leaf trait plasticity to alter ecosystem functioning could act directly, without changes in plant type abundance, as well as indirectly, through changes in plant competitive dynamics and thus the relative abundance of different plant types.

Among the most commonly observed plant trait responses to experimentally elevated $\mathrm{CO}_{2}$ are increases in leaf mass per area (LMA, $g$ leaf carbon $m^{-2}$ leaf area) and the ratio of carbon to nitrogen within leaves (C: $\mathrm{N}_{\text {leaf }}, g$ leaf carbon $g^{-1}$ leaf nitrogen). Observations suggest that each of these leaf traits could increase by as much as one-third under doubled $\mathrm{CO}_{2}$ in a wide range of tropical tree species spanning successional classes (Fig. 1; Lovelock et al., 1998; Reekie \& Bazzaz, 1989; Winter et al., 2000; Winter \& Lovelock, 1999) implying thicker leaves with lower mass-based nitrogen concentrations. Comparison of Earth system model simulations to observations at ecosystem-scale $\mathrm{CO}_{2}$ enrichment experiments suggests that accurately representing these two leaf traits is critical to predicting ecosystem responses to elevated $\mathrm{CO}_{2}$ (Zaehle et al., 2014; De Kauwe et al., 2014; Medlyn et al., 2015). Fisher et al. (2019) also found that LMA was a critical control over the responsiveness of ecosystems in the CLM5 land surface model.

The leading hypothesis for why $\mathrm{C}: \mathrm{N}_{\text {leaf }}$ and LMA increase with elevated $\mathrm{CO}_{2}$ is that $\mathrm{CO}_{2}$ fertilization leads to nitrogen limitation of plant growth and the accumulation of nonstructural carbohydrates in leaves (Winter et al., 2001; Poorter et al., 2009, 1997; Pritchard et al., 1999; Roumet et al., 1999; Meyerholt \& Zaehle, 2015). This is also consistent with the prediction from optimality approaches which suggest that higher $\mathrm{CO}_{2}$ should lead to lower allocation to rubisco in favor of allocating the nitrogen to other parts of the plant (Xu et al., 2012; Quebbeman \& Ramirez, 2016; Smith et al., 2019). While both LMA and C: $\mathrm{N}_{\text {leaf }}$ trait changes have potential benefits (discussed below), it is possible that these changes are forced upon plants as there is not enough nitrogen to retain default leaf traits under high $\mathrm{CO}_{2}$. It is possible that even if plastic responses of LMA and $\mathrm{C}: \mathrm{N}_{\text {leaf }}$ do not lead to increased assimilation they could still benefit plants, i.e. by allowing for more efficient use of $\mathrm{N}$ across the plant. Here we impose a range of $\mathrm{C}: \mathrm{N}_{\text {leaf }}$ and LMA plasticity levels and quantify the total canopy nitrogen required to support each leaf trait plasticity level.

\subsection{Direct effects of trait plasticity}

Plasticity in C: $\mathrm{N}_{\text {leaf }}$ and LMA directly influence tropical forest functioning by altering area-based photosynthetic rates. $\mathrm{C}: \mathrm{N}_{\text {leaf }}$ is the amount of nitrogen present in a given unit of leaf mass, with higher $\mathrm{C}: \mathrm{N}_{\text {leaf }}$ indicating a lower amount of nitrogen per unit leaf mass. LMA describes the mass used to construct a unit of leaf area. Together these two traits control the nitrogen per leaf area $\left(\mathrm{N}_{\text {area }}, g\right.$ nitrogen $m^{-2}$ leaf area) as follows:

$$
N_{\text {area }}=\frac{L M A}{C: N_{\text {leaf }}}
$$

Given that nitrogen is an essential component of photosynthetic enzymes, particularly rubisco, $\mathrm{N}_{\text {area }}$ is an important determinant of maximum photosynthetic rates per leaf area (Drake \& Gonzàlez-Meler, 1997; Kattge et al., 2009, 2011; Walker et al., 2014; Norby et al., 2017). $\mathrm{N}_{\text {area }}$ is therefore used in many terrestrial biosphere models to es- 
timate photosynthetic parameters, which in turn exert strong influence over modeled carbon uptake (Verheijen et al., 2013; Bonan et al., 2011; Walker et al., 2017; Rogers et al., 2017). Changes in maximum photosynthetic rates due to altered $\mathrm{N}_{\text {area }}$ can also influence rates of evapotranspirative cooling, as transpiration is coupled to photosynthesis in all commonly used stomatal conductance algorithms (Ball et al., 1987; Medlyn et al., 2011).

Experimental manipulation of $\mathrm{CO}_{2}$ in tropical forest systems has been observed to modify both LMA and C: $\mathrm{N}_{\text {leaf }}$ in a wide range of tropical tree species across successional classes (Lovelock et al., 1998). These observations suggest that co-occurring changes in LMA and C: $\mathrm{N}_{\text {leaf }}$ in response to a doubling of $\mathrm{CO}_{2}$ most often caused $\mathrm{N}_{\text {area }}$ to decrease (Fig. 1 below diagonal line) or, in fewer cases, to be maintained (Fig. 1 on diagonal line; Lovelock et al., 1998). Thus, in the absence of other changes (such as adjusted partitioning of nitrogen between different photosynthetic processes; e.g., Xu et al., 2012; Leakey, Ainsworth, et al., 2012; Smith et al., 2019) the observed leaf trait plasticity in response to elevated $\mathrm{CO}_{2}$ has the potential to lower projections of tropical ecosystem carbon uptake and evapotranspirative cooling by reducing photosynthetic rates and stomatal conductance.

Leaf trait plasticity could also directly influence ecosystem functioning by modifying leaf area index (LAI, $\mathrm{m}^{2}$ leaf area $\mathrm{m}^{-2}$ ground), which provides the surface area over which photosynthesis and transpiration are scaled to the ecosystem level. Increasing LMA increases the carbon cost of building leaf area, as thicker leaves require more carbon to build a given unit of leaf area. For a given unit mass of carbon allocation to leaves, LMA is, by definition, used to calculate plant leaf area. In terms of nutrient budgets, for a constant $\mathrm{C}: \mathrm{N}_{\text {leaf }}$, increasing LMA also increases nitrogen requirements, while increasing C: $\mathrm{N}_{\text {leaf }}$ makes leaf area less expensive in terms of nitrogen. In models, these dynamics are of course only applicable when active nitrogen cycling is represented.

There are direct trade-offs between the influences of leaf plasticity on C: $\mathrm{N}_{\text {leaf }}$ and LMA on photosynthetic rates and leaf area under elevated $\mathrm{CO}_{2}$. Increases in $\mathrm{C}: \mathrm{N}_{\text {leaf }}$ could reduce maximum photosynthetic rates but do not alter the carbon cost of building leaf area while increases in LMA could offset reductions in maximum photosynthetic rates due to higher $\mathrm{C}: \mathrm{N}_{\text {leaf }}$ but increase the cost of building leaf area. Thus, given both the conflicting impacts of increasing C: $\mathrm{N}_{\text {leaf }}$ and LMA on $\mathrm{N}_{\text {area }}$, and the secondary impacts on leaf area itself, the likely net response of ecosystems to elevated $\mathrm{CO}_{2}$ taking into account this type of leaf trait plasticity is not immediately apparent. While some nitrogenenabled models allow for flexible C:N stoichiometry (Zaehle \& Friend, 2010; Ghimire et al., 2016; Fisher et al., 2019; Caldararu et al., 2020), we are unaware of studies that have specifically included these direct and indirect effects of plasticity in response to forcing for LMA. Further, changes in leaf area and leaf functioning incur changes in respiratory costs as well. The resulting trade-offs of changes in leaf traits for both per leaf area and total canopy rates of functioning thus depend on assumptions about how respiratory costs scale with either total leaf mass or total mass of nitrogen.

\subsection{Indirect effects of trait plasticity}

Competition for light is recognized to be a dominant driver of community composition in tropical forests (e.g., Sterck et al., 2011). In addition to the direct influences described above, tropical tree responses to increasing $\mathrm{CO}_{2}$ could also indirectly change ecosystem functioning by altering plant competition for light and the relative abundance of different plant types (reviewed by Cusack et al., 2016). The magnitude of leaf trait responses to elevated $\mathrm{CO}_{2}$ has been observed to differ among tropical tree species (Lovelock et al., 1998; Reekie \& Bazzaz, 1989; Winter et al., 2000; Winter \& Lovelock, 1999). Variation in leaf trait plasticity across tropical tree types could lead to differential changes in the competitive ability for light in response to elevated $\mathrm{CO}_{2}$ and thus alter the abun- 
dance of competing plant types. LMA and $\mathrm{C}: \mathrm{N}_{\text {leaf }}$ act to modify both leaf area index and biomass through their influence on per leaf area photosynthetic rates as well as total leaf area. Leaf area index and biomass in turn can influence plant competitive ability. In general, trees which accumulate less biomass may not be able to grow as tall as their neighbors and may therefore become more heavily shaded; while trees with lower leaf area index may not be able to capture as much light or shade their neighbors in competition for light. Thus changes in these traits are likely to differentially alter the competitive ability of individual trees depending on their magnitude of plasticity.

\subsection{Results from previous studies}

Observational manipulation experiments have shown that tropical tree trait responses to $\mathrm{CO}_{2}$ are species-specific (Lovelock et al., 1998; Reekie \& Bazzaz, 1989; Winter et al., 2000; Winter \& Lovelock, 1999) and suggest that differences in $\mathrm{CO}_{2}$ responses across species could lead to changes in community structure (reviewed by Cusack et al., 2016). Investigating the relationship between individual traits and community outcomes is challenging in empirical studies due to multiple, confounding changes in plants treated with elevated $\mathrm{CO}_{2}$ (Lovelock et al., 1998; Reekie \& Bazzaz, 1989). While increases in C: $\mathrm{N}_{\text {leaf }}$ and increases in LMA both appear to have negative impacts on plants at first consideration each has the potential to confer advantage. Despite first-order reductions in nitrogen per unit plant area, increasing $\mathrm{C}: \mathrm{N}_{\text {leaf }}$ may benefit plants as an adaptation to $\mathrm{N}$ limited conditions. McMurtrie et al. (2008) showed that a temperate monoculture was able to maximize productivity under limited nitrogen availability and elevated $\mathrm{CO}_{2}$ by increasing $\mathrm{C}: \mathrm{N}_{\text {leaf }}$ which enabled increased leaf area. Increasing LMA could also be beneficial despite the higher cost of leaf area. Previous modeling studies have used observations of LMA and C: $\mathrm{N}_{\text {leaf }}$ change to simulate changes in assimilation and individual plant growth and found that increasing LMA helps to offset negative effects of higher $\mathrm{C}: \mathrm{N}_{\text {leaf }}$ on $\mathrm{N}_{\text {area }}$ and photosynthetic rates per leaf area under elevated $\mathrm{CO}_{2}$ (Luo et al., 1994; Ishizaki et al., 2003).

None of these studies, however, considered communities of plants or the effects of competition between different plant types, nor did they focus on tropical tree species. Other modeling studies have found variability in plant traits, such as LMA, to have strong influences on plant competition for resources and ecosystem functioning under elevated $\mathrm{CO}_{2}$ (Ali et al., 2015; Verheijen et al., 2015; Fisher et al., 2010). For example, Ali et al. (2015) found that decreasing LMA (the opposite of the observed change) was beneficial to competitive success under elevated $\mathrm{CO}_{2}$, but did not consider the observed concomitant changes in $\mathrm{C}: \mathrm{N}_{\text {leaf }}$. Thus it remains unclear how the combination of observed trait responses to $\mathrm{CO}_{2}$ will influence plant competitive dynamics, the survival of responsive trees, and tropical ecosystem structure and functioning in the future. Additionally, Verheijen et al. (2015) allowed LMA to vary with $\mathrm{CO}_{2}$ (along with other environmental drivers and traits) globally in a dynamic global vegetation model, however they didn't allow LMA influence leaf area index, nor, did they focus on tropical trees.

\subsection{Modeling Objectives}

In this study we explore how plasticity in two key leaf traits mediates tropical ecosystem carbon uptake and evapotranspirative cooling responses to a doubling of $\mathrm{CO}_{2}$ using an ensemble of simulations of the Functionally Assembled Terrestrial Ecosystem Simulator (FATES; Fisher et al., 2015; Koven et al., 2020) vegetation demographic model at a tropical forest test site, Barro Colorado Island, Panama. We investigate how different levels of plasticity in C: $\mathrm{N}_{\text {leaf }}$ and LMA (gray squares in Fig. 1) in response to a doubling of $\mathrm{CO}_{2}$ : 1) modify ecosystem level carbon uptake and evapotranspirative cooling in the absence of competition; 2) alter biomass and leaf area index; and 3) alter competitive outcomes when two plant types with different leaf trait plasticity responses compete. 


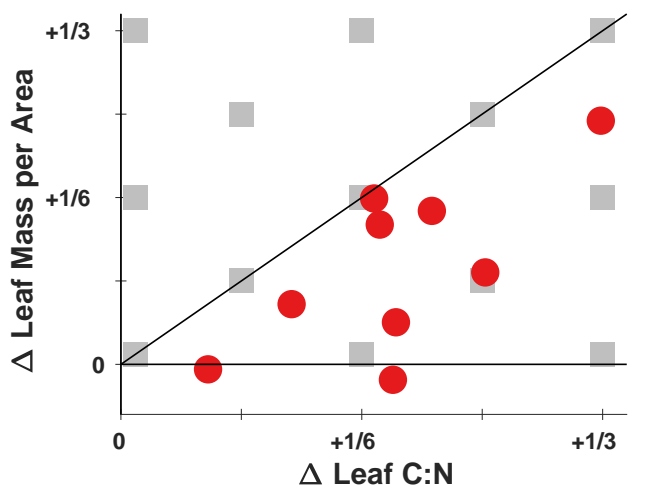

Figure 1. Leaf trait plasticity in response to a doubling of $\mathrm{CO}_{2}$ in tropical trees for leaf $\mathrm{C}: \mathrm{N}$ (leaf $\left.g C g N^{-1}\right)$ and leaf mass per area $\left(g C \mathrm{~m}^{-2}\right.$ leaf area). Observed changes across nine tropical tree species (red circles) from Lovelock et al. (1998). Leaf trait plasticity levels sampled for our experiments (gray squares). Diagonal black line indicates where nitrogen per area $\left(\mathrm{N}_{\text {area }}\right.$, $g N m^{-2}$ leaf area) remains at control levels. Above the diagonal line nitrogen per area increases $\left(+\mathrm{N}_{\text {area }}\right)$ compared to the control; below the diagonal line it decreases $\left(-\mathrm{N}_{\text {area }}\right)$.

We test leaf trait plasticity levels that increase $\left(+\mathrm{N}_{\text {area }}\right)$, decrease $\left(-\mathrm{N}_{\text {area }}\right)$, and maintain $\mathrm{N}_{\text {area }}\left(=\mathrm{N}_{\text {area }}\right)$. Our simulations do not explicitly represent growth limitation by or competition for nitrogen. Instead, we are able to quantify the change in total canopy nitrogen ( $g$ nitrogen $\mathrm{m}^{-2}$ ground) required to support an ecosystem with each level of leaf trait plasticity (under doubled $\mathrm{CO}_{2}$ ). We find that leaf trait plasticity levels that decrease $\mathrm{N}_{\text {area }}$, - consistent with observed responses of LMA and C: $\mathrm{N}_{\text {leaf }}$, could reduce projections of future carbon uptake and evapotranspiration in the absence of competition. However, trees that are able to maintain or increase $\mathrm{N}_{\text {area }}$ under high $\mathrm{CO}_{2}$ would likely have a competitive advantage and could therefore maintain higher levels of ecosystem carbon uptake and evapotranspirative cooling.

\section{Methods}

\subsection{Model Overview}

We use an ensemble of simulations of the Functionally Assembled Terrestrial Ecosystem Simulator (FATES; Fisher et al., 2015; Massoud et al., 2019; Koven et al., 2020) embedded within the Community Land Model version 5 (Lawrence et al., 2018) to test the influence of leaf trait plasticity on tropical ecosystem functioning and competitive dynamics. CLM(FATES) is a cohort-based vegetation demographic model (Fisher et al., 2018; Koven et al., 2020), that mechanistically simulates plant ecological dynamics and ecosystem assembly via processes including plant growth, competition for light, recovery from disturbance, reproduction, mortality, and recruitment. A key feature of the model, based on the ecosystem demography concept (Moorcroft et al., 2001), is that it resolves distributions of vegetation height and time since disturbance, which allows it to simulate competition for light. In the model, disturbance, from tree mortality, fire, or logging, occurs at some rate across patches of the simulated ecosystem. Plants grow upon ground area within these "patches", which are tracked by an age that represents the time since the last disturbance that that area of ground experienced. Within a patch, individual plants are grouped into "cohorts", which can differ in height and functional type. Thus, cohorts represent individual plants of the same plant type and height as a representative average individual. The height structure of cohorts within a patch determines 
the light profile experienced by each cohort. The leaf area of taller cohorts in the canopy can shade cohorts deeper in the canopy, which is further depicted as discrete canopy layers using the perfect plasticity approximation (Purves et al., 2008). Photosynthesis, respiration, turnover, and mortality, as well as the interaction of these processes with the abiotic environment, control the amount of carbon each cohort can use for growth. Growth and size-dependent allometric equations then determine the height, biomass, and target leaf area of each cohort. Thus, carbon uptake is dynamic and influences plant growth, leaf area, and size, which in turn influence competition for light. Radiation streams for direct and diffuse light are calculated at the leaf layer level for each plant type, patch and canopy layer. This incoming energy drives photosynthesis and the surface energy budget, and thus rates of carbon uptake and transpiration. In sum, the model tracks fluxes of carbon, water, and energy throughout the ecosystem. This version of CLM(FATES) does not explicitly represent growth limitation by or competition for nutrients, thus, we implement C: $\mathrm{N}_{\text {leaf }}$ and LMA plasticity levels that represent the potential influences of nutrient limitation and quantify the total canopy nitrogen required to support each leaf trait plasticity level.

Baseline parameters for the model (Table S1) were chosen from a parameter ensemble that sampled plant parameters from observations when possible following the methods of Koven et al. (2020) and described in Kovenock (2019). In brief, Kovenock (2019) sampled 287 plausible parameterizations from the tropical tree trait space for 12 parameters, 6 of which were based on observations (see further discussion in Supporting Information Text S1.1 and Kovenock, 2019). Our primary results used the parameterization that allowed the simulated ecosystem to best match present day measurements of leaf area index, above-ground biomass, basal area, net primary productivity, latent heat fluxes, and sensible heat fluxes at our test site, Barro Colorado Island, Panama (also used in Koven et al., 2020). We further test the sensitivity of our results to the next two best performing parameter sets. (See Supporting Information Text S1.1 and S2.1 for details.)

\subsection{Leaf trait plasticity estimation and implementation}

Our experiments test 13 levels of leaf plasticity in C: $\mathrm{N}_{\text {leaf }}$ and LMA sampled from the two-dimensional leaf trait plasticity space in Fig. 1 (gray squares). We test the equilibrium response to elevated $\mathrm{CO}_{2}$ rather than representing dynamic changes in time. The leaf trait plasticity space represents both observed (at or below diagonal line in Fig. 1) and hypothetical (above the diagonal line in Fig. 1) levels of leaf trait plasticity. The observed leaf trait plasticity space is estimated from observations of leaf responses to a doubling of $\mathrm{CO}_{2}$ in nine tropical tree species, including early, mid- and late successional classes (Lovelock et al., 1998, Fig. 1 red circles), and supported by additional studies in tropical trees and many other C3 plant types (e.g., Lovelock et al., 1998; Reekie \& Bazzaz, 1989; Winter et al., 2000; Winter \& Lovelock, 1999). These observations suggest that both C: $\mathrm{N}_{\text {leaf }}$ and LMA could increase by as much as one-third in response to a doubling of $\mathrm{CO}_{2}$ while $\mathrm{N}_{\text {area }}$ (Eqn 1) decreases or remains constant. Thus, we define observed leaf trait plasticity levels as those that maintain $\mathrm{N}_{\text {area }}$ at $\left(=\mathrm{N}_{\text {area }}\right)$ or below $\left(-\mathrm{N}_{\text {area }}\right)$ control (CTRL and CC) levels. We also test leaf trait plasticity levels that increase $\mathrm{N}_{\text {area }}$ $\left(+\mathrm{N}_{\text {area }}\right)$, to determine if such a response could help tropical trees enhance their productivity and competitive ability. Given the wide diversity of tropical tree species it is possible that some tropical tree species, (e.g. those with traits that enhance nutrient foraging or fixing capabilities), could in principle increase $\mathrm{N}_{\text {area }}$ (Fig. 1 above diagonal line) in response to higher $\mathrm{CO}_{2}$.

Changes in C: $\mathrm{N}_{\text {leaf }}$ and LMA in our simulations drive changes in $\mathrm{N}_{\text {area }}$, maximum photosynthetic and respiration rates, and leaf area index. Plasticity in C: $\mathrm{N}_{l e a f}$ and LMA drives changes in $\mathrm{N}_{\text {area }}$ (as described above) and this in turn alters maximum rates of photosynthesis (e. g. $\mathrm{V}_{\operatorname{cmax}}, \mathrm{J}_{\max }, \mathrm{T}_{\text {pmax }}$ ) and leaf respiration, following Eqn 1. We directly implement changes in $\mathrm{V}_{\text {cmax } 25}$ to vary in proportion to $\mathrm{N}_{\text {area }}$ (which was allowed 
to change with changes to $\mathrm{C}: \mathrm{N}_{\text {leaf }}$ and LMA). Changes in the other maximum photosynthetic rates, $\mathrm{J}_{\max 25}$ and $\mathrm{T}_{\text {pmax } 25}$, are thus also altered as they are are calculated by the model in proportion to $\mathrm{V}_{\text {cmax 25 }}$. Changes in maximum rates of photosynthesis and leaf respiration assume no changes in nitrogen partitioning among photosynthetic enzymes (c.f. Xu et al., 2012). We assume that LMA decreases with canopy depth following the observations of Lloyd et al. (2010) as previously implemented in FATES by Kovenock (2019). In FATES, leaf area index responds dynamically to carbon available for leaf growth, reducing canopy depth until no leaf layers are in negative annual carbon balance (Fisher et al., 2015). See further discussion in Supporting Information Text S1.2 for details.

\subsection{Simulations}

We ran simulations for a tropical forest test site at Barro Colorado Island in Panama. All simulations were forced with repeating meteorological data from this site from the years 2003-2016 (Faybishenko et al., 2018). All of our simulations used one or two broadleaf evergreen tropical trees, characteristic of our tropical forest test site. This plant functional type represents an average of many species within the evergreen tropical tree plant type, and thus here is not meant to resolve trait distinctions between species or successional classes. Two control simulations represent a baseline tropical forest ecosystem without leaf trait plasticity. The first control simulates the ecosystem with $\mathrm{CO}_{2}$ concentration fixed at $400 \mathrm{ppm} \mathrm{CO}_{2}\left(\mathrm{CTRL} ; 1 \mathrm{xCO}_{2}\right)$. The second control is identical to the first except that the ecosystem experiences a fixed atmospheric $\mathrm{CO}_{2}$ concentration of $800 \mathrm{ppm}$ $\left(\mathrm{CC} ; 2 \mathrm{xCO}_{2}\right)$. Plants in these control simulations do not experience leaf trait plasticity in response to elevated $\mathrm{CO}_{2}$ (gray square at origin in Fig. 1). The difference between the control simulations (CC - CTRL) quantifies the influence of $\mathrm{CO}_{2}$ fertilization on the baseline simulated tropical ecosystem. Meteorological air temperature does not change in response to elevated $\mathrm{CO}_{2}$ in our simulations to reflect the experimental conditions under which the leaf plasticity was observed. We chose these two levels of $\mathrm{CO}_{2}$ concentration to represent a doubling of $\mathrm{CO}_{2}$ from current conditions which results in a similar change but slightly higher baseline values compared to the conditions imposed in (Lovelock et al., 1998) from which we draw empirical inference for the magnitude of trait response of tropical trees.

We quantify the direct influence of different degrees of leaf trait plasticity, in the absence of competition, using an ensemble of simulations that are identical to the $2 \mathrm{xCO}_{2}$ control (CC). Each ensemble member imposes a different level of leaf trait plasticity (gray squares sampled from leaf trait plasticity space in Fig. 1) on all plants in the simulation. We call these simulations of the ecosystem "in absence of competition" because different plant types that compete against each other are not present. We further group leaf trait plasticity experiments by whether they decrease $\left(-\mathrm{N}_{\text {area }}\right.$, below diagonal line in Fig. $1)$, maintain $\left(=\mathrm{N}_{\text {area }}\right.$, on diagonal line in Fig. 1$)$, or enhance $\mathrm{N}_{\text {area }}\left(+\mathrm{N}_{\text {area }}\right.$, above diagonal line in Fig. 1). We calculate the total canopy nitrogen required for each "in absence of competition" simulation as total canopy leaf carbon ( $g$ leaf C $m^{-2}$ ground) divided by $\mathrm{C}: \mathrm{N}_{\text {leaf }}\left(g \mathrm{C} g \mathrm{~N}^{-1}\right)$.

We test the influence of leaf trait plasticity level on competitive ability using a second ensemble of simulations, which we refer to as "pairwise competition" simulations. These simulations are identical to the $2 \mathrm{xCO}_{2}$ control (CC) except that each experiment includes two different plant types with identical initial conditions, which are identical in all traits except in their level of leaf trait plasticity. The two plant types are allowed to compete for light within the ecosystem. We repeat these pairwise competition experiments for all factorial combinations of two levels of leaf trait plasticity sampled from the species-specific points in leaf trait plasticity space (gray squares in Fig. 1), including the control "no leaf trait plasticity" plant type (gray square at origin in Fig. 1). We find that in each competition simulation, one plant type (i.e. one level of leaf trait plasticity) always eventually out-competes the other. For an analysis of the dynamics of co- 
existence in the FATES model see Koven et al. (2020). We define one plant type as "winning" the competition when it overtakes at least two-thirds of the total ecosystem biomass (see below for further details). We quantify differences in competitive ability due to leaf trait plasticity using a measure called percent wins (\% wins), which is the percent of all pairwise competitions a plant type with a given leaf trait plasticity level wins across competition with the other plant types in the ensemble.

The $1 \mathrm{xCO}_{2}$ control simulation (CTRL) was started from near-bare ground and integrated for 700 years. All variables came into equilibrium within 450 years, the time required to grow a mature forest with our model set up. The $2 \mathrm{xCO}_{2}$ control simulation (CC) and all experiments were branched from the $1 \mathrm{xCO}_{2}$ control simulation (mature forest) at year 500 and experienced an abrupt doubling of $\mathrm{CO}_{2}$ to a time-invariant concentration of $800 \mathrm{ppm} \mathrm{CO}_{2}$. The $2 \mathrm{xCO}_{2}$ control and experiment simulations were run to the point that the community was dominated by one plant type considered the "winner". Specifically, every simulation was run for 3,500 years, at which point $99 \%$ of competitions between plant types with different trait changes were complete (one plant type reached at least $95 \%$ of the ecosystem biomass). In the remaining $1 \%$ of competitions one plant type had become dominant (taken over at least $67 \%$ of ecosystem biomass and trending towards overtaking all ecosystem biomass). We analyze the last 100 years of each simulation as our equilibrium ecosystem.

\subsection{Statistical Analysis}

We quantify the influence of leaf trait plasticity in the absence of competition (i.e. simulations with only one plant type) using 1) differences in annual mean ecosystem properties and 2) relationships between leaf trait plasticity levels and annual mean ecosystem properties across simulations. We use bootstrap methods with model years as the unit of replication $(\mathrm{n}=50,000)$ to construct confidence intervals for annual mean leaf area index, biomass, net primary productivity, evapotranspiration, and total canopy nitrogen and test for differences between simulations. We use bootstrapping methods because some variables have time series that are non-normally distributed, have unequal variances, and temporal autocorrelation. The 100 model years we analyze for each variable are unique despite repeating the 14 years of meteorological forcing, as ecological dynamics also influence the environment (e.g., light availability) and ecosystem structure and functioning in our simulations. We use simple, multiple, and stepwise linear regression methods to test for relationships between leaf trait plasticity levels (C: $\mathrm{N}_{\text {leaf }}$, LMA, $\mathrm{N}_{\text {area }}$ ) and annual mean ecosystem properties across simulations. Correlations between percent wins and annual mean net primary productivity and evapotranspiration across simulations were tested using Pearson's linear correlation coefficient. Differences, relationships, and correlations were considered statistically significant at the $95 \%$ confidence level. (See Supporting Information Text S1.4 for details.)

\section{Results}

\subsection{Elevated $\mathrm{CO}_{2}$ response in the control simulation}

Previous observations, simulations, and theory show that elevated atmospheric $\mathrm{CO}_{2}$ concentration enhances photosynthesis and reduces stomatal conductance, which has the potential to enhance productivity and reduce evapotranspiration at the ecosystem scale (e.g, Cernusak et al., 2013; Cusack et al., 2016; Lloyd \& Farquhar, 2008; Zhu et al., 2016; Lloyd \& Farquhar, 2008; Swann et al., 2016; De Kauwe et al., 2013, and references therein). In our control simulation (no leaf trait plasticity) a doubling of atmospheric $\mathrm{CO}_{2}$ concentration from $400 \mathrm{ppm}$ to $800 \mathrm{ppm}$ (CC-CTRL) increases annual mean net primary productivity $(+74.2 \%)$, leaf area index $(+7.0 \%)$, and biomass $(+102.6 \%)$, and reduces evapotranspiration $(-9.2 \%)$ (Table 1, Fig. 2). As noted in the methods section, the FATES model we use here does not explicitly represent nutrient limitation, thus we directly im- 

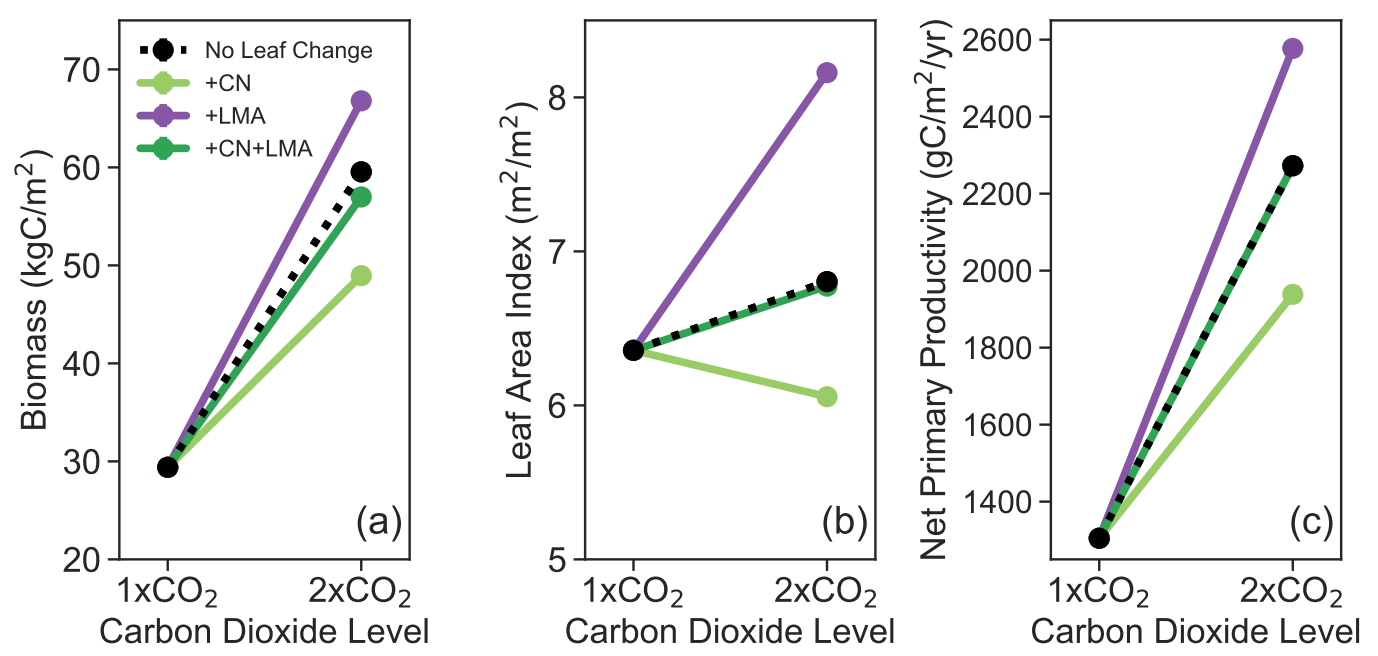

Figure 2. Annual mean (a) biomass $\left(k g C m^{-2}\right)$ and (b) leaf area index $\left(m^{2} m^{-2}\right)$ and (c) net primary productivity $\left(g \mathrm{C} \mathrm{m}^{-2} \mathrm{~s}^{-1}\right)$ for the $1 \mathrm{xCO}_{2}$ control, $2 \mathrm{xCO}_{2}$ control (black), and the following leaf trait plasticity levels in the absence of competition: a one-third increase in leaf $\mathrm{C}: \mathrm{N}$ alone $(+\mathrm{CN}$, light green), a one-third increase in leaf mass per area alone (+LMA, purple), and a one-third increase in both leaf $\mathrm{C}: \mathrm{N}$ and leaf mass per area (+CN+LMA, dark green). A bootstrap $95 \%$ confidence interval for the mean value all fall within the size of the markers.

plement leaf trait changes in our experiments that represent potential influences of nutrient limitation and quantify the total canopy nitrogen required to support each leaf trait plasticity level.

The actual expected magnitude of tropical forest responses to elevated $\mathrm{CO}_{2}$ is highly uncertain and little experimental data exists, particularly at the ecosystem scale (Lloyd \& Farquhar, 2008; Hickler et al., 2008; Mahowald et al., 2016; Cusack et al., 2016; Norby et al., 2016; Fleischer et al., 2019; Holm et al., 2020). However, our control simulation response to elevated $\mathrm{CO}_{2}$ shows reasonable agreement with observations from temperate forest FACE experiments (De Kauwe et al., 2013, 2014) if one assumes a linear scaling with increasing $\mathrm{CO}_{2}$ (Cernusak et al., 2019). For example, a $+200 \mathrm{ppm} \mathrm{CO}_{2}$ increase at Duke Forest enhanced net primary productivity by approximately $30 \%$ (De Kauwe et al., 2013), which when scaled to $+400 \mathrm{pm}$ results in a $+60 \%$ increase in net primary productivity (we find $+74.2 \%$, in the absence of N limitation). Similarly, when scaled to $+400 \mathrm{ppm}$ these FACE experiments saw changes equivalent to approximately $+6 \%$ and $+30 \%$ in leaf area index at Oak Ridge and Duke, respectively (we find $+7 \%$ ) ; $-40 \%$ in transpiration at Oak Ridge (no significant change at Duke Forest) (we find $+9.2 \%$ ); and $+100 \%$ in biomass increment at Duke (we find total biomass changes, which are not directly equivalent, of $+102 \%$ ). Thus our modeled changes are all roughly comparable with these ranges, with slightly higher modeled increases in net primary productivity in our tropical simulations compared to these observational estimates from temperate forests. Lastly, changes in each of these ecosystem properties in our control simulation also fall within the simulated ranges from 11 Earth system models at these two temperate forest FACE sites after linearly scaling for $\mathrm{CO}_{2}$ concentration (De Kauwe et al., 2013, 2014). While our control simulation response to elevated $\mathrm{CO}_{2}$ is comparable to those estimated from observations in temperate forests, tropical forest responses may of course be subject to different constraints (e.g., De Graaff et al., 2006; Luo et al., 2006; Hickler et al., 2008; Zaehle et al., 2014; Fleischer et al., 2019). Davies-Barnard et al. (2020) illustrate that for five CMIP6 class models with active nitrogen cycles, the fertilization impact of 
+200ppm $\mathrm{CO}_{2}$ had a mean net primary productivity response of $16-18 \%$ for models other than CLM4.5 (which has an anomalously strong $\mathrm{N}$ limitation) which is about half the size of what we find $(37 \%$ for $+200 \mathrm{ppm})$. These models, however, are all subject to $\mathrm{N}$ limitation, and also show strong spatial variation, with tropical forests showing higher than average simulated $\mathrm{CO}_{2}$ fertilization rates.

\subsection{Influence of leaf trait plasticity on canopy structure in absence of competition}

We find that imposed leaf trait plasticity alters net primary productivity, biomass, and leaf area index responses to a doubling of $\mathrm{CO}_{2}$ in the absence of competition (Fig. 2). Under elevated $\mathrm{CO}_{2}$, increasing $\mathrm{C}: \mathrm{N}_{\text {leaf }}$ by one-third (the upper bound of our observed range) diminishes the increase in net primary productivity $\left(-334 \mathrm{gCm}^{-2} \mathrm{~s}^{-1}\right)$ and biomass $\left(-10.6 \mathrm{kgCm}^{-2}\right)$, as well as decreasing leaf area index $\left(-0.7 \mathrm{~m}^{2} \mathrm{~m}^{-2}\right)$ compared to the control plant type (CN - CC). In contrast, increasing LMA by one-third enhances the increases in both simulated biomass $\left(+7.2 \mathrm{kgCm}^{-2}\right)$ and leaf area index $\left(+1.4 \mathrm{~m}^{2} \mathrm{~m}^{-2}\right)$ compared to the control plant type (LMA - CC), via increases in net primary productivity $\left(+304 \mathrm{gCm}^{-2} \mathrm{~s}^{-1}\right)$ from increasing $\mathrm{N}_{\text {area }}$ that has a larger effect than the more costly leaf construction. Increasing both $\mathrm{C}: \mathrm{N}_{\text {leaf }}$ and LMA simultaneously by one-third under a doubling of $\mathrm{CO}_{2}$ (CNLMA) results in only a slightly reduced increase in biomass $\left(-2.6 \mathrm{kgCm}^{-2}\right)$ and no change in leaf area index $\left(0.0 \mathrm{~m}^{2} \mathrm{~m}^{-2}\right)$ or net primary productivity $\left(-0.8 \mathrm{gCm}^{-2} \mathrm{~s}^{-1}\right)$ compared to the control plant type (CNLMA - CC).

The first-order impacts are that, for any given increase in C: $\mathrm{N}_{\text {leaf }}$, a simultaneous increase in LMA allows plants to maintain biomass and leaf area index that are closer to the control plant type. It is worth noting additionally that the simultaneous change is not a perfect cancellation between the two factors. When LMA increases in isolation leaves get thicker and more productive per area with increased $\mathrm{N}_{\text {area }}$. When $\mathrm{C}: \mathrm{N}_{\text {leaf }}$ is increased, $\mathrm{N}_{\text {area }}$ and net primary productivity decrease. When both factors occur simultaneously, thicker leaves compensate for a lower mass density of nitrogen. The two factors cancel one another out in terms of net primary productivity, as $\mathrm{N}_{\text {area }}$ is conserved, however biomass is reduced slightly relative to the case with no leaf change. We hypothesize that this happens because thicker leaves require more carbon allocated to leaves relative to wood and thus the overall whole plant turnover of carbon is faster resulting in a smaller total biomass. Consistent with this hypothesis, we find that the fractional allocation of net primary productivity to leaves goes up even for the case where $\mathrm{N}_{\text {area }}$ is conserved (by +0.023 , see Table $\mathrm{S} 2$ ), and the lifetime of total biomass decreases (by -0.72 years, see Table S2).

\subsection{Influence of leaf trait plasticity on competitive ability}

We find that the control plant type, with no leaf trait plasticity (and thus no change in $\mathrm{N}_{\text {area }}$ ), is more competitively advantageous than all leaf trait plasticity levels sampled where $\mathrm{N}_{\text {area }}$ either decreases or remains constant under a doubling of $\mathrm{CO}_{2}$ (Fig. 3). The control plant type (origin in Fig. 3) wins all of pairwise competitions against plant types with leaf trait plasticity levels sampled from the trait changes that maintain $\mathrm{N}_{\text {area }}$ $\left(=\mathrm{N}_{\text {area }}\right.$, along black dashed diagonal line in Fig. 3$)$ or reduce $\mathrm{N}_{\text {area }}\left(-\mathrm{N}_{\text {area }}\right.$, below black dashed diagonal line in Fig. 3).

Increasing C: $\mathrm{N}_{\text {leaf }}$ strongly diminished competitive ability, as evidenced by the decreasing percentage of competitions a plant type wins as $\mathrm{C}: \mathrm{N}_{\text {leaf }}$ increases (left to right, Fig. 3). At a given $\mathrm{C}: \mathrm{N}_{\text {leaf }}$, increasing LMA typically enhances competitive ability. At very high $\mathrm{C}: \mathrm{N}_{\text {leaf }}$ there is little change, (bottom to top, Fig. 3) however, reflecting the trade-off between the impacts on $\mathrm{N}_{\text {area }}$ (reduced productivity) and leaf area index (increased productivity). This results from decreased net primary productivity, biomass, and leaf area index, as $\mathrm{N}_{\text {area }}$ is reduced (Fig. 4). 
These results from our competition experiments are consistent with our findings in the absence of competition-higher $\mathrm{C}: \mathrm{N}_{\text {leaf }}$ leads to lower net primary productivity, biomass, and leaf area index and increasing LMA results in net primary productivity, biomass, and leaf area index gains (Fig. 2). However, LMA increases sampled from plasticity levels that maintain or decrease $\mathrm{N}_{\text {area }}$ do not, in this model, fully compensate for the negative influence of higher $\mathrm{C}: \mathrm{N}_{\text {leaf }}$ on competitive ability at any level. Furthermore, the competitive benefit of increasing LMA diminishes at higher C: $\mathrm{N}_{\text {leaf }}$, as evidenced by the sinusoidal shape of the $50 \%$ wins shading (white) in Fig. 3. In sum, we find that plant types that can maintain higher $\mathrm{N}_{\text {area }}$ in high $\mathrm{CO}_{2}$, have greater competitive ability.

Leaf trait plasticity levels that enhance $\mathrm{N}_{\text {area }}\left(+\mathrm{N}_{\text {area }}\right.$, above diagonal line in Fig. 3 ) enhance competitive ability compared to the control leaf type, as well as all leaf trait plasticity levels sampled from the $=\mathrm{N}_{\text {area }}$ and $-\mathrm{N}_{\text {area }}$ space (Fig. 3). This is consistent with our finding that increasing LMA in isolation enhances biomass and leaf area index beyond the control case in the absence of competition (Fig. 2).

\subsection{Changes in carbon uptake and evapotranspirative cooling}

Ecosystem carbon uptake is tightly coupled to changes in LMA and C: $\mathrm{N}_{\text {leaf }}$, both directly via their impacts on photosynthetic rate, and indirectly via impacts on leaf area index. In our experiments we impose changes in leaf traits, which result in emergent rates of carbon uptake, while in a fully evolving system we expect that the carbon uptake rates and nutrient availability are likely involved in setting the leaf traits to begin with (see further discussion in section 4.3). Evapotranspiration is additionally a downstream result of stomatal conductance and leaf area index. Given that the meteorological conditions are the same in our experiments and our control, the changes in ET that we found result from changes to plant traits and functioning only, and tend to change in concert with carbon fluxes. Leaf trait plasticity levels sampled from the $-\mathrm{N}_{\text {area }}$ space are associated with lower carbon uptake and evapotranspiration compared to the control response to a doubling of $\mathrm{CO}_{2}(\mathrm{CC})$ in our experiments reflecting the influence of reduced photosynthetic capacity (Fig. 5, Table 1). On average the observed changes in C: $\mathrm{N}_{\text {leaf }}$ and LMA reduce the increase in annual mean net primary productivity by $-9.2 \%$ and further reduce annual mean ET by $-4.4 \%$ compared to the $2 \mathrm{xCO}_{2}$ control $\left(-\mathrm{N}_{\text {area }}-\mathrm{CC}\right)$. The largest reduction in net primary productivity $(-14.7 \%)$ and evapotranspiration $(-7.0 \%)$ results from the leaf trait plasticity level that increases $\mathrm{C}: \mathrm{N}_{\text {leaf }}$ by one-third without a co-occurring increase in LMA (CN - CC), a response which was not specifically observed by Lovelock et al. (1998).

Leaf trait plasticity levels that maintain $\mathrm{N}_{\text {area }}$ equal to the control $\left(=\mathrm{N}_{\text {area }}\right)$ also maintain carbon uptake and evapotranspiration at control levels (Fig. 5, Table 1). Annual mean net primary productivity and evapotranspiration do not differ significantly between $=\mathrm{N}_{\text {area }}$ simulations and the control simulation under a doubling of $\mathrm{CO}_{2}\left(=\mathrm{N}_{\text {area }}\right.$ - CC). Leaf changes that enhance $\mathrm{N}_{\text {area }}\left(+\mathrm{N}_{\text {area }}\right)$ increase carbon uptake and moderate the reduction in evapotranspiration compared to the control response to a doubling of $\mathrm{CO}_{2}$ (Fig. 5, Table 1). On average $+\mathrm{N}_{\text {area }}$ leaf trait plasticity levels increase annual mean net primary productivity by $+8.4 \%$ and lessen the reduction in evapotranspiration by $+4.8 \%\left(+\mathrm{N}_{\text {area }}-\mathrm{CC}\right)$. The largest enhancement of net primary productivity $(+13.4 \%)$ and evapotranspiration $(+7.9 \%)$ results from the leaf trait plasticity level that increases LMA by one-third but does not alter C: $\mathrm{N}_{\text {leaf }}$ (LMA - CC).

Leaf trait plasticity levels that confer a higher competitive advantage also have a higher carbon uptake (Fig. 5). We expect that more $\mathrm{N}_{\text {area }}$ generally leads to higher productivity and thus higher associated evapotranspiration. The competitive ability of a plant type with a given level of leaf trait plasticity, as measured by the percent of competi- 
tions won against plant types with other levels of plasticity (percent wins), is significantly correlated with net primary productivity $(\mathrm{r}=0.91)$ and evapotranspiration $(\mathrm{r}=0.91)$.

\subsection{Total canopy nitrogen}

Progressive nitrogen limitation is hypothesized to limit plant growth in response to elevated $\mathrm{CO}_{2}$ (Luo et al., 2004) and may be a cause of $\mathrm{C}: \mathrm{N}_{\text {leaf }}$ and LMA plasticity in response to elevated $\mathrm{CO}_{2}$ (Poorter et al., 2009, 1997; Pritchard et al., 1999; Roumet et al., 1999; Meyerholt \& Zaehle, 2015). Here we report the total amounts of canopy nitrogen required for ecosystems with differing levels of leaf trait plasticity, and compare them to the $1 \mathrm{xCO}_{2}$ control simulation (CTRL), which provides a reference for the amount of nitrogen used by canopies in the simulated current day ecosystem. Variation in total canopy nitrogen across simulations results from the leaf trait plasticity changes we imposed and changes in overall leaf carbon, which is an emergent property of each simulation.

Under $1 \mathrm{xCO}_{2}$ conditions, our control simulation (CTRL) had a total canopy nitrogen content of $8.3 \mathrm{gNm}^{-2}$ ground. Doubling $\mathrm{CO}_{2}$ increased the control ecosystems total canopy nitrogen content by $+0.3 \mathrm{gNm}^{-2}$ or $+3.2 \%$ (Fig. 3 red contours). This increase is only due to the increase in leaf biomass, which at the canopy level in FATES is governed by a combination of within-plant optimization of leaf biomass to maximize canopy carbon export combined with the ability of plants to survive in the understory, both of which are expected to promote slightly higher leaf carbon under the elevated $\mathrm{CO}_{2}$ conditions. Leaf trait plasticity levels that maintain $\mathrm{N}_{\text {area }}$ at control levels $\left(=\mathrm{N}_{\text {area }}\right)$ but have increases in both $\mathrm{C}: \mathrm{N}_{\text {leaf }}$ and LMA also increase the total amount of canopy nitrogen required beyond the $1 \mathrm{xCO}_{2}$ control level, although by slightly less than the $2 \mathrm{xCO}_{2}$ control, with the mean change across $=\mathrm{N}_{\text {area }}$ simulations ranging from $2.1 \%$ to $3.0 \%\left(=\mathrm{N}_{\text {area }}\right.$ - CTRL; Fig. 3). The $-\mathrm{N}_{\text {area }}$ scenarios all maintain canopy $\mathrm{N}$ content at or below the $1 \mathrm{xCO}_{2}$ control level (- $\mathrm{N}_{\text {area }}$; Fig. 3 ). Simulation with high $\mathrm{C}: \mathrm{N}$ and unchanged LMA lowered canopy $\mathrm{N}$ content by as much as $-23.2 \%$.

\section{Discussion}

\subsection{Large-scale climate implications}

We find that observed changes in leaf C:N ratios and LMA reduce model predictions of tropical tree productivity, evapotranspiration, and competitive ability under high $\mathrm{CO}_{2}$ and alter carbon and water fluxes, with implications for projections of future largescale climate. We expect that reductions in evapotranspirative cooling over tropical forests would lead directly to local warming (Kovenock \& Swann, 2018). Reductions in carbon uptake leave more $\mathrm{CO}_{2}$ in the atmosphere thus if such reductions were to be widespread over tropical forests there might be global scale implications for warming through the greenhouse effect of $\mathrm{CO}_{2}$ (Kovenock \& Swann, 2018). We find that, as is intuitive, tropical trees which are more able to maintain their leaf nitrogen per unit area near present day levels have the highest competitive abilities and also show the smallest changes in carbon and water fluxes (Fig. 5), suggesting that if changes in plant type abundance shift to reflect the most competitive members of the community this will allow maintenance of higher gas exchange rates, leaf area index, and biomass.

\subsection{Constraints from canopy nitrogen budgets}

Maintaining present-day leaf $\mathrm{N}_{\text {area }}$ with a doubling of $\mathrm{CO}_{2}$ requires an increase in canopy nitrogen for the control case (CC; red contour lines in Fig. 3) to support the increase in leaf area index (Fig. 2). Thus if we assume that ecosystem N limitation imposes a requirement for conservation of canopy $\mathrm{N}_{\text {area }}$, this limits the possible leaf trait plasticity space by excluding the control and central diagonal band along with the en- 


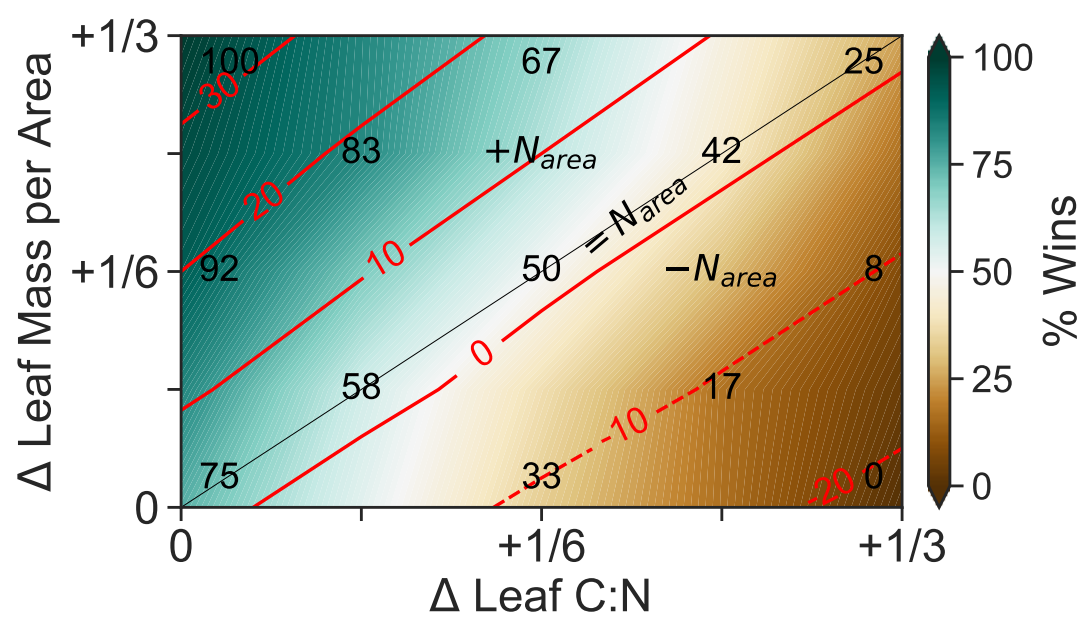

Figure 3. The percent of pairwise competitions won (\% Wins, color shading and black numbers) and percent change in total canopy nitrogen compared to the $1 \mathrm{xCO}_{2}$ control (red contours) for each leaf trait plasticity level of leaf C:N and leaf mass per area. Percent wins for sampled trait changes (black numbers). Diagonal line (dashed black) indicates where nitrogen per area $\left(\mathrm{N}_{\text {area }}, g N m^{-2}\right.$ leaf area) remains at control levels $\left(=\mathrm{N}_{\text {area }}\right)$. Leaf trait plasticity levels below the diagonal line reduce $\mathrm{N}_{\text {area }}\left(-\mathrm{N}_{\text {area }}\right)$ compared to the control plant type. Leaf trait plasticity levels above the diagonal line enhance $\mathrm{N}_{\text {area }}\left(+\mathrm{N}_{\text {area }}\right)$ compared to the control plant type. Linear interpolation used to estimate percent wins and change in total canopy nitrogen between sampled trait changes.

tire upper-left triangle in Fig. 3. This limitation of nitrogen may thus partially explain why the control case, where LMA and C: $\mathrm{N}_{\text {leaf }}$ are simultaneously conserved, is not observed in the real world. Although phosphorus limitation is thought to be the primary nutrient constraint on plant growth in the tropics, evidence from empirical studies and manipulation experiments suggests that tree growth is also limited by nitrogen in the tropics (e.g. Winter et al., 2001; reviewed in Cernusak et al., 2013). Most of the changes in leaf traits observed by Lovelock et al. (1998) show reduced $\mathrm{N}_{\text {area }}$, which in our simulations leads to a reduction in total canopy nitrogen. This could be due to a change in nitrogen allocation. For example, nitrogen allocation to roots could increase or increases in woody biomass could require greater total amounts of nitrogen (see discussion below).

\subsection{Why do leaf changes occur?}

Our model results suggest that, in the context of the FATES parameterization used here, observed increases in C: $\mathrm{N}_{\text {leaf }}$ in response to elevated $\mathrm{CO}_{2}$ do not confer a competitive advantage. We find that plant types in which $\mathrm{C}: \mathrm{N}_{\text {leaf }}$ increases in response to elevated $\mathrm{CO}_{2}$ suffer in several metrics of plant fitness, including biomass, leaf area index, net primary productivity, and competitive ability. Thus our results suggest that changes in $\mathrm{C}: \mathrm{N}_{\text {leaf }}$ are likely forced upon plants by changes in elevated $\mathrm{CO}_{2}$, rather than occurring as a beneficial acclimation. This is consistent with the leading hypothesis for the mechanism underlying C: $\mathrm{N}_{\text {leaf }}$ increases with elevated $\mathrm{CO}_{2}$. Nitrogen limitation has been proposed as a cause for lower mass-based nitrogen concentrations in leaves (e.g., Poorter et al., 1997; Winter et al., 2001; Fyllas et al., 2009; Cusack et al., 2016). As carbon dioxide fertilizes plant growth the demand for nutrients is likely to increase and eventually result in the depletion of nitrogen available for growth (Luo et al., 2004; Hungate et al., 2003). The limited availability of nitrogen, as well as accumulation of nonstructural car- 

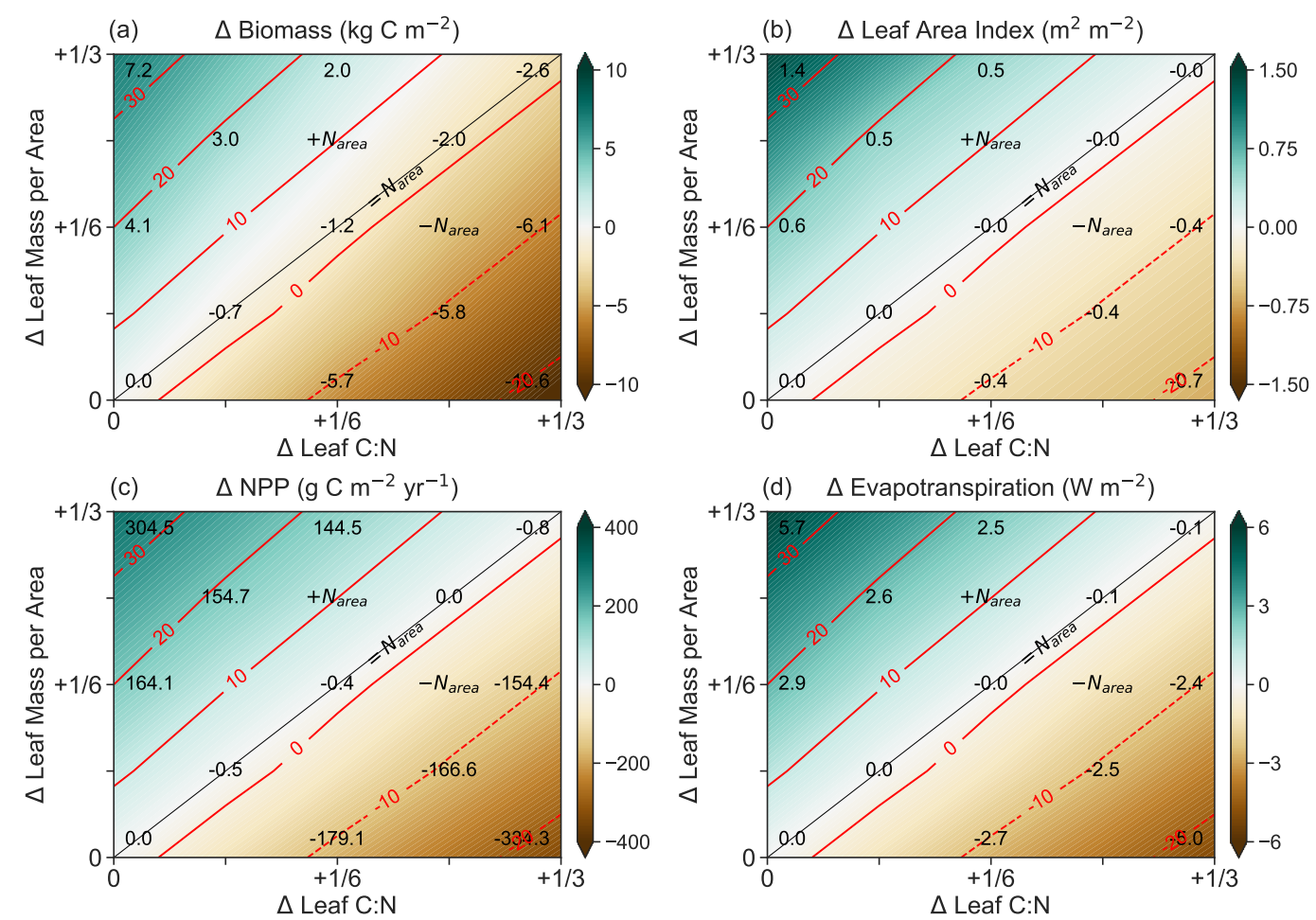

Figure 4. Changes in (a) biomass $\left(k g C \mathrm{~m}^{-2}\right)$, (b) leaf area index $\left(\mathrm{m}^{2} \mathrm{~m}^{-2}\right)$, (c) net primary productivity $\left(g C \mathrm{~m}^{-2} \mathrm{yr}^{-1}\right)$, and (d) evapotranspiration $\left(W \mathrm{~m}^{-2}\right)$ compared to the $2 \mathrm{xCO}_{2}$ control (color shading and black numbers) and percent change in total canopy nitrogen compared to the $1 \mathrm{xCO}_{2}$ control (red contours, identical on all plots) for each leaf trait plasticity level of leaf C:N and leaf mass per area. Diagonal line (dashed black) indicates where nitrogen per area $\left(\mathrm{N}_{\text {area }}, g N \mathrm{~m}^{-2}\right.$ leaf area) remains at control levels. Leaf trait plasticity levels at or below the diagonal line reduce $\mathrm{N}_{\text {area }}\left(-\mathrm{N}_{\text {area }}\right)$ compared to the control plant type. Leaf trait plasticity levels above the diagonal line enhance $\mathrm{N}_{\text {area }}\left(+\mathrm{N}_{\text {area }}\right)$ compared to the control plant type. Changes were measured for sampled trait changes (black numbers). Linear interpolation used to estimate changes between sampled trait changes. 

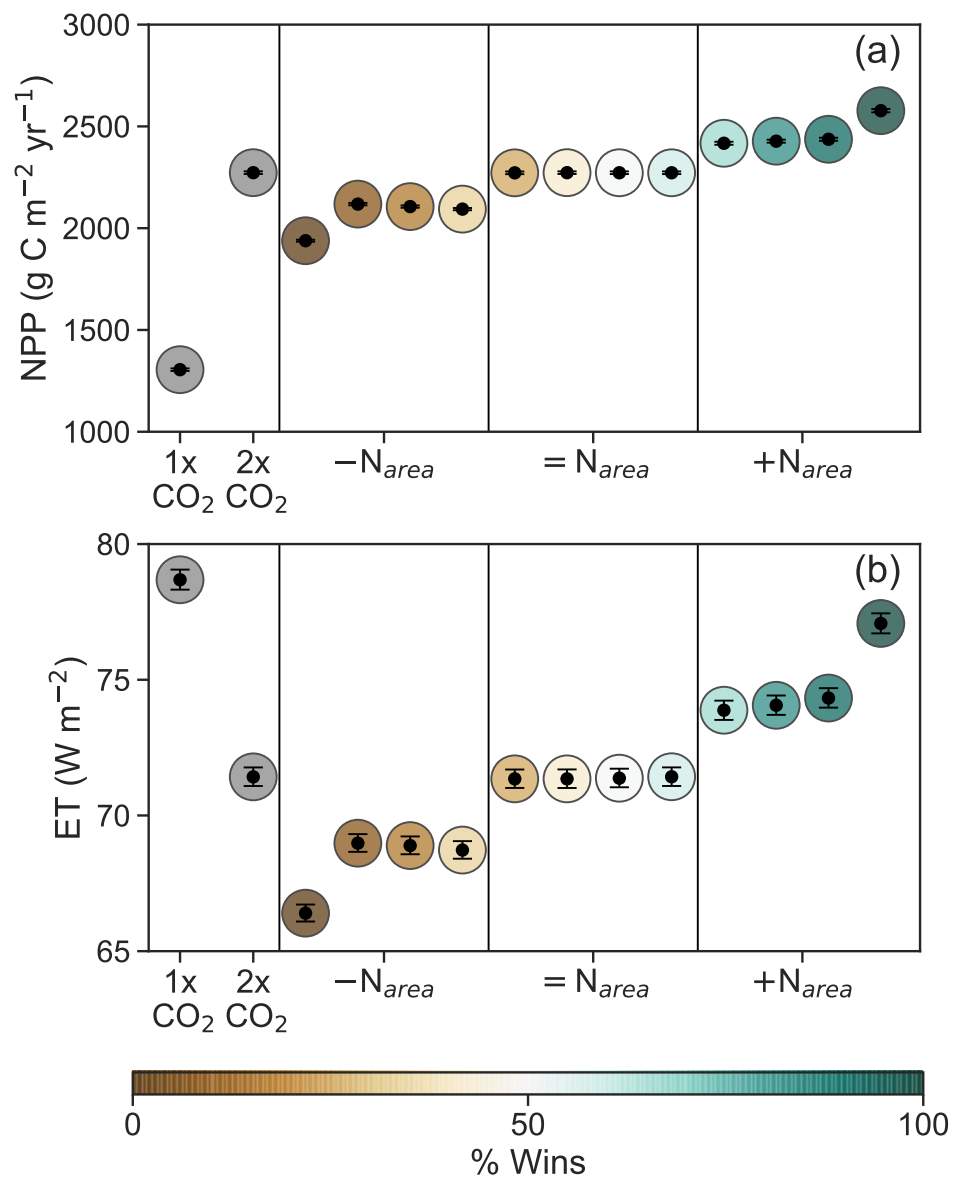

Figure 5. Annual mean (a) net primary productivity (NPP, $g C m^{-2} y r^{-1}$ ) and (b) evapotranspiration (ET, $W m^{-2}$ ) for the $1 \mathrm{xCO}_{2}$ control, $2 \mathrm{xCO}_{2}$ control (no leaf trait plasticity), and 12 ecosystems each consisting entirely of one plant type with a different level of leaf trait plasticity sampled from the $-\mathrm{N}_{\text {area }},=\mathrm{N}_{\text {area }}$, and $+\mathrm{N}_{\text {area }}$ trait plasticity spaces. Color indicates the percentage of all pairwise competitions won by each level of leaf trait plasticity (\% Wins). Error bars show bootstrap $95 \%$ confidence intervals for the mean value. 
bohydrates due to sink limitation of growth, could lower mass-based leaf nitrogen concentrations and result in higher C: $\mathrm{N}_{\text {leaf }}$ (e.g., Poorter et al., 1997; Winter et al., 2001). Manipulation experiments in which tropical tree seedlings are treated with elevated $\mathrm{CO}_{2}$ provide evidence that $\mathrm{CO}_{2}$ stimulation of growth is enhanced by the addition of soil nutrients, suggesting that nutrient limitation does indeed impact leaf trait responses (Winter et al., 2001). Plants in which C: $\mathrm{N}_{\text {leaf }}$ increases more in response to elevated $\mathrm{CO}_{2}$ may be those that are unable to adjust to lower nitrogen availability or higher competition for nitrogen. Tropical trees with traits that allow them to better acquire nitrogen, for example associations with nitrogen fixing bacteria or fungi, may be better able to maintain C: $\mathrm{N}_{\text {leaf }}$ levels under elevated $\mathrm{CO}_{2}$ with advantages for growth and competitive success (Lovelock et al., 1998; Cusack et al., 2016; Cernusak et al., 2013).

Further, it has been suggested that the increase in LMA with elevated $\mathrm{CO}_{2}$ is mediated by nitrogen (or other resource limitation of plant growth causing nonstructural carbohydrates accumulation in leaves; Poorter et al., 2009, 1997; Pritchard et al., 1999; Roumet et al., 1999). We find that coordinated responses of both LMA and C: $\mathrm{N}_{\text {leaf }}$ are beneficial: plants that are able to increase LMA most for a given level of C: $\mathrm{N}_{\text {leaf }}$ change are those that are best able to maintain high biomass, leaf area index, productivity, and competitive ability. Concurrently increasing LMA along with C: $\mathrm{N}_{\text {leaf }}$ leads to maintenance of equal $\mathrm{N}_{\text {area }}$ by counteracting decreases in mass-based nitrogen concentration (Luo et al., 1994; Ishizaki et al., 2003). Indeed, we found that even when limited to control levels of total canopy nitrogen, plants could maintain close to equal amounts of $\mathrm{N}_{\text {area }}$. As nitrogen is an essential component of photosynthetic enzymes, maintaining $\mathrm{N}_{\text {area }}$ can maintain area-based maximum photosynthetic rates (Kattge et al., 2009, 2011; Walker et al., 2014; Norby et al., 2017), and we find that net primary productivity closely follows the amount of $\mathrm{N}_{\text {area }}$ in our simulations. Observations by Lovelock et al. (1998) of tropical tree leaf trait responses to a doubling of $\mathrm{CO}_{2}$ (Fig. 1) suggest that increases in LMA are generally higher for larger increases in C: $\mathrm{N}_{\text {leaf }}$, helping to maintain $\mathrm{N}_{\text {area }}$ and thus functioning - closer to control levels (Fig. 5). While it is logical that increasing LMA concurrently with C: $\mathrm{N}_{\text {leaf }}$ is advantageous to plants, this leaves open the question of why these two factors would change in the first place if canopy nitrogen is the limiting constraint.

\subsection{Other potential leaf trait plasticity trade-offs}

Other coordinated plant plasticity responses to elevated $\mathrm{CO}_{2}$ and nutrient limitation could further influence the impacts of leaf trait plasticity on competitive ability and tropical forest functioning. Observations show that many trees, including tropical trees, enhance carbon and nitrogen allocation to root growth at the expense of leaf growth in response to elevated $\mathrm{CO}_{2}$ (e.g., Luo et al., 2006, Körner and Arnone, 1992; reviewed in Cusack et al., 2016; Cernusak et al., 2013). Such partitioning of nitrogen away from leaves could increase $\mathrm{C}: \mathrm{N}_{\text {leaf }}$ but benefit plants if they use the nitrogen to build other structures that help alleviate resource limitation, such as roots that can access further nutrients (reviewed in Cusack et al., 2016; Cernusak et al., 2013) although, in some cases, this growth strategy has been found to be ineffective (Norby et al., 2010). Our primary results isolate the influence of leaf trait plasticity changes and do not include changes in the target ratio of root mass to leaf area. However, we test the sensitivity of our results to increasing target root mass in coordination with leaf trait plasticity using additional simulations (Supporting Information Text S1.3.2 and S2.1). In these additional experiments, trees increase target root mass in proportion with increases in LMA. This accounts for the additional carbon cost of growing more roots to support the additional nutrient requirements for greater leaf mass. This makes it even more costly to increase LMA, which we expect should reduce the competitive advantage of doing so. In this case, we find that the control plant type is always at competitive advantage, and the benefit of increasing LMA that we saw in our primary results no longer consistently occurs 
(Fig. S3). This result highlights the importance of considering the whole plant system and coordinated trade-offs that might occur under modified environmental conditions.

Other potential trade-offs for leaf trait plasticity responses could be thought to alter their influence on tropical forest ecosystem dynamics and functioning. For example, enhanced leaf lifespan is associated with greater LMA across species (Wright et al., 2004) and could be expected to further enhance productivity and competitive outcomes. However, this relationship across species does not necessarily hold within species (Anderegg et al., 2018; Fisher et al., 2015; Lusk et al., 2008) and varies in response to elevated carbon dioxide (Norby et al., 2003, 2010; Taylor et al., 2008; Lovelock et al., 1998), thus we chose not to couple increases in leaf lifespan with increases in LMA in our experiments. Higher carbon to nitrogen ratios are also associated with defense against herbivory (reviewed in Cusack et al., 2016), which could increase with climate change (e.g. Deutsch et al., 2018) but are not considered in our simulations.

\subsection{Indirect effects of plant type abundance}

With limited changes in spatial distributions of plant types, the observed plastic response of plants under high $\mathrm{CO}_{2}$ is likely to lead to decreases in $\mathrm{N}_{\text {area }}$ and thus to overall decreases in carbon uptake and evapotranspirative cooling. On the other hand, if the distribution of plants in an ecosystem changes due to differences in competitive ability, plant types that can maintain higher $\mathrm{N}_{\text {area }}$ and thus confer greater competitive advantage could, in the longer term, increase in abundance and bring carbon uptake and evapotranspirative cooling more in line with projections that assume leaf traits remain as in the control.

\subsection{Potential role of rising temperatures}

Warming temperatures could be expected to alter the response of leaf traits to $\mathrm{CO}_{2}$, with implications for the influence of leaf trait plasticity on ecosystem functioning and composition. For example, warmer temperatures have been found to be associated with lower leaf nitrogen content across a spatial gradients in present-day tropical forests (Cusack et al., 2016; Fyllas et al., 2009; Tully \& Lawrence, 2010), plausibly via the negative impacts of plant respiration with high nitrogen content (Cernusak et al., 2013). Such decreases in leaf nutrient concentration could amplify the leaf responses to elevated $\mathrm{CO}_{2}$ we test here (unless there were accompanying changes in the allocation of $\mathrm{N}$ to different plant processes). Higher temperatures have been associated with lower LMA in manipulation experiments (Poorter et al., 2009), as well as across an elevational gradient in present-day tropical forests (Doughty et al., 2018). This influence could be expected to offset the LMA increase in response to $\mathrm{CO}_{2}$ we test here. However, warming and $\mathrm{CO}_{2}$ are hypothesized to influence LMA through different mechanisms (leaf expansion vs. accumulation of carbohydrates, respectively), making it difficult to predict the combined influence of these two environmental factors on LMA. Thus, the combined influence of elevated $\mathrm{CO}_{2}$ and temperature on tropical tree traits remains poorly constrained (Cusack et al., 2016; Cernusak et al., 2013).

\subsection{Recommendations for including leaf trait plasticity in projections of future climate}

We illustrate here that a better understanding of tropical tree responses to environmental change, as well as the use of plant competition models, will be needed to accurately include the effects of leaf trait plasticity in projections of future climate.

First, more observations are required to constrain tropical tree leaf responses to multiple environmental factors - including $\mathrm{CO}_{2}$, nutrient availability, and temperature - and how these responses differ by tree type (e.g. successional class or species) and develop- 
mental stage (e.g. Cusack et al., 2016). Our ability to characterize leaf trait plasticity in response to environmental change may ultimately require a better understanding of whole plant carbon and nutrient dynamics, as leaf carbon and nitrogen can depend on supply and demand from other plant organs (e.g. Luo et al., 1994; Pritchard et al., 1999; Norby et al., 2010; Xu et al., 2012; Winter et al., 2001; Zaehle et al., 2014).

Second, numerous models of the terrestrial biosphere represent the cycling of nutrients, and a subset of these represent flexibility in tissue C:N ratios in response to $\mathrm{N}$ availability (Zaehle \& Friend, 2010; Zaehle et al., 2014). Here we show that simulation of changes in $\mathrm{C}: \mathrm{N}$ ratio in isolation of apparently coordinated changes in LMA may overestimate the impact of changing stoichiometry on future gas exchange. Complex as it is, models should thus strive to represent the temporal dynamics of important plant traits themselves - including LMA — under changing environmental conditions. Here we test the impacts of modifying plant traits as observed, but many studies aim to predict such plant properties from principles of evolutionary optimality theory (McMurtrie \& Dewar, 2011; Prentice et al., 2014; Dewar et al., 2012; Thomas \& Williams, 2014; Xu et al., 2012), for example, to maximize leaf or canopy carbon export per unit $\mathrm{N}$ investment, or similar metrics. Optimality models typically predict single optimal solutions for a given set of conditions, without consideration of demographic time lags or genetic limitations on trait plasticity. Vegetation demographic models, wherein competing plants might move the community mean towards an optimum, provide an alternative means of predicting plant trait dynamics in time (Weng et al., 2015; Falster et al., 2017; Fisher et al., 2018). Using a model of plant competition, we show here that changes in leaf traits can alter plant competitive dynamics and the abundance of different plant types with implications for ecosystem functioning. Ideally, some consideration of the degree to which traits are plastic within existing species would provide the best means to combining these two approaches (Fisher \& Koven, 2020), but would require detailed studies of limits to plasticity (e.g. Geange et al., 2017; Power et al., 2019). Consideration of alternative optimal approaches to trait prediction will be investigated in future versions of FATES.

\subsection{Implications}

Here we show that leaf trait plasticity in response to elevated $\mathrm{CO}_{2}$ could alter tropical forest influences on climate directly, by altering the functioning of tropical trees, and indirectly, by modifying plant competitive dynamics and the abundance of different plant types. As such, including the effects of leaf trait plasticity could have a significant influence on projections of future climate. These results further support the need for more observations of tropical tree responses to environmental change and the use of plant competition models within earth system models used to predict future climate change.

\section{Acknowledgments}

MK, ALSS, CDK, RAF designed the study, all authors contributed to model development, MK completed the simulations, MK analyzed the output, all authors contributed to interpretations of the results, and MK, ALSS wrote the paper with input from all authors. We thank Janneke Hille Ris Lambers an Elizabeth Van Volkenburgh for their insightful suggestions on an earlier version of this manuscript. We acknowledge support from the National Science Foundation AGS-1553715 to the University of Washington. RAF acknowledges the support of the National Center for Atmospheric Research, which is a major facility sponsored by the National Science Foundation under Cooperative Agreement 1852977. CDK acknowledges support by the Director, Office of Science, Office of Biological and Environmental Research of the U.S. Department of Energy (DOE BER) under Contract DE-AC02-05CH11231 through the Early Career Research Program, the Regional and Global Model Analysis Program (RUBISCO SFA). CDK, RAF, and RGK acknowledge support from the DOE-BER Next Generation Ecosystem Experiment-Tropics (NGEE-Tropics) project. All simulations were run on the National Center for Atmospheric 


\begin{tabular}{|c|c|c|c|c|c|}
\hline & \multicolumn{2}{|c|}{ Biomass $\left(k g C m^{-2}\right)$} & \multicolumn{2}{|c|}{ LAI $\left(m^{2} m^{-2}\right)$} & $\operatorname{NPP}\left(g C m^{-2} y r^{-1}\right)$ \\
\hline & Mean $\left(\mathrm{CI}_{95}\right)$ & $\%\left(\mathrm{CI}_{95}\right)$ & Mean $\left(\mathrm{CI}_{95}\right)$ & $\%\left(\mathrm{CI}_{95}\right)$ & Mean $\left(\mathrm{CI}_{95}\right) \%\left(\mathrm{CI}_{95}\right)$ \\
\hline \multirow{2}{*}{ double $\mathrm{CO}_{2}$} & 30.1 & 102.6 & 0.45 & 7 & $\begin{array}{ll}967.8 & 74.2\end{array}$ \\
\hline & $(30,30.2)$ & $(102.1,103)$ & $(0.43,0.46)$ & $(6.8,7.2)$ & $(958.8,976.8)(73.2,75.1)$ \\
\hline \multirow{2}{*}{$-\mathrm{N}_{\text {area }}$} & -7.1 & -11.9 & -0.5 & -7.4 & $\begin{array}{lll}4 & -208.6 & -9.2\end{array}$ \\
\hline & $(-7.1,-7)$ & $(-12,-11.7)$ & $(-0.51,-0.49)$ & $(-7.5,-7.2)$ & $(-215.7,-201.6)(-9.5,-8.9)$ \\
\hline \multirow{2}{*}{$=\mathrm{N}_{\text {area }}$} & -1.6 & -2.7 & -0.02 & -0.3 & $\begin{array}{llll}3 & -0.4 & 0\end{array}$ \\
\hline & $(-1.7,-1.5)$ & $(-2.9,-2.6)$ & $(-0.03,-0.01)$ & $(-0.4,-0.1)$ & $(-7.7,6.8) \quad(-0.3,0.3)$ \\
\hline \multirow{2}{*}{$+\mathrm{N}_{\text {area }}$} & 4.1 & 6.9 & 0.76 & 11.1 & $\begin{array}{lll}1 & 191.9 & 8.4\end{array}$ \\
\hline & $(4,4.2)$ & $(6.7,7)$ & $(0.75,0.77)$ & $(10.9,11.3)$ & $(184.4,199.6)$ \\
\hline \multirow{2}{*}{$+\mathrm{CN}$} & -10.6 & -17.8 & -0.75 & -11 & $\begin{array}{lll}1 & -334.3 & -14.7\end{array}$ \\
\hline & $(-10.7,-10.5)$ & $(-18,-17.6)$ & $(-0.76,-0.74)$ & $(-11.1,-10.8)$ & $(-342.4,-326.3)(-15,-14.4)$ \\
\hline \multirow{2}{*}{$+\mathrm{LMA}$} & 7.2 & 12.2 & $2 \quad 1.36$ & 20 & $\begin{array}{lll}0 & 304.5 & 13.4\end{array}$ \\
\hline & $(7.1,7.4)$ & $(11.9,12.4)$ & $(1.34,1.38)$ & $(19.7,20.2)$ & $(294.2,314.9)(12.9,13.9)$ \\
\hline \multirow{4}{*}{$+\mathrm{CN}+\mathrm{LMA}$} & -2.6 & -4.3 & -0.03 & -0.4 & $\begin{array}{lll}4 & -0.8 & 0\end{array}$ \\
\hline & $(-2.7,-2.4)$ & $(-4.5,-4.1)$ & $(-0.04,-0.02)$ & $(-0.6,-0.3)$ & $(-9.9,8.4) \quad(-0.4,0.4)$ \\
\hline & \multicolumn{2}{|c|}{$\operatorname{ET}\left(W m^{-2}\right)$} & \multicolumn{2}{|c|}{ Total Canopy $\mathrm{N}\left(g N m^{-2}\right)$} & \\
\hline & Mean $\left(\mathrm{CI}_{95}\right)$ & $\%\left(\mathrm{CI}_{95}\right)$ & Mean $\left(\mathrm{CI}_{95}\right)$ & $\%\left(\mathrm{CI}_{95}\right)$ & \\
\hline double $\mathrm{CO}_{2}$ & $\begin{array}{r}-7.3 \\
(-7.8,-6.8)\end{array}$ & $\begin{array}{r}-9.2 \\
(-9.8,-8.6)\end{array}$ & $\begin{array}{r}0.26 \\
(0.26,0.27)\end{array}$ & $\begin{array}{r}3.2 \\
(3.1,3.3)\end{array}$ & \\
\hline$-\mathrm{N}_{\text {area }}$ & $\begin{array}{r}-3.2 \\
(-3.6,-2.8)\end{array}$ & $\begin{array}{r}-4.4 \\
(-5,-3.9)\end{array}$ & 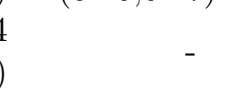 & (5) & \\
\hline$=\mathrm{N}_{\text {area }}$ & $\begin{array}{r}0 \\
(-0.4,0.3)\end{array}$ & $\begin{array}{r}-0.1 \\
(-0.6,0.5)\end{array}$ & ) & & \\
\hline$+\mathrm{N}_{\text {area }}$ & $\begin{array}{r}3.4 \\
(3,3.8)\end{array}$ & $\begin{array}{r}4.8 \\
(4.2,5.3)\end{array}$ & 8 & & \\
\hline$+\mathrm{CN}$ & $\begin{array}{r}-5 \\
(-5.5,-4.6)\end{array}$ & $\begin{array}{r}-7 \\
(-7.7,-6.4)\end{array}$ & $\begin{array}{r}-1.93 \\
(-1.93,-1.92)\end{array}$ & $\begin{array}{r}-23.2 \\
(-23.3,-23.2)\end{array}$ & \\
\hline+ LMA & $\begin{array}{r}5.7 \\
(5.1,6.2)\end{array}$ & $\begin{array}{r}7.9 \\
(7.2,8.6)\end{array}$ & $\begin{array}{r}3.02 \\
(3,3.03)\end{array}$ & $\begin{array}{r}36.3 \\
(36.2,36.5\end{array}$ & \\
\hline$+\mathrm{CN}+\mathrm{LMA}$ & $\begin{array}{r}-0.1 \\
(-0.6,0.4)\end{array}$ & $\begin{array}{r}-0.1 \\
(-0.8,0.6)\end{array}$ & $\begin{array}{r}0.18 \\
(0.17,0.18)\end{array}$ & $\begin{array}{r}2.1 \\
(2.1,2.2)\end{array}$ & \\
\hline
\end{tabular}

Biomass, Leaf area index (LAI), net primary productivity (NPP), evapotranspiration (ET), and total canopy nitrogen (total canopy N) mean and percent (\%) changes. "Double $\mathrm{CO}_{2}$ " mean and percent changes are calculated as (CC - CTRL) and (CC CTRL)/CTRL, respectively, where CTRL and CC are the control simulations at $400 \mathrm{ppm}$ and $800 \mathrm{ppm} \mathrm{CO}_{2}$, respectively. All other mean and percent changes are calculated as (Experiment - CC) and (Experiment - CC)/CC, where CC is the control simulation at $800 \mathrm{ppm} \mathrm{CO}_{2}$ and Experiment refers to experiments with different leaf trait plasticity levels. Bootstrap $95 \%$ confidence intervals $\left(\mathrm{CI}_{95} \%\right)$ in parentheses. $-\mathrm{N}_{\text {area }},=\mathrm{N}_{\text {area }}$, and $+\mathrm{N}_{\text {area }}$ average across experiments with leaf trait plasticity levels that decrease, maintain, and enhance leaf nitrogen per area, respectively. $+\mathrm{CN}$ experiment increases $\mathrm{C}: \mathrm{N}_{\text {leaf }}$ by one-third; +LMA increases LMA by one-third; and +CN+LMA, simultaneously increases $\mathrm{C}: \mathrm{N}_{\text {leaf }}$ and LMA by one-third.

Table 1. 
Research's Cheyenne system. High-performance computing support from Cheyenne (doi:10.5065/D6RX99HX) was provided by NCAR's Computational and Information Systems Laboratory, sponsored by the National Science Foundation. Model output used in this study is available through the University of Washington Libraries ResearchWorks digital repository at http:// hdl. handle.net/1773/46218.

\section{References}

Ali, A. A., Medlyn, B. E., Aubier, T. G., Crous, K. Y., \& Reich, P. B. $\quad$ (2015, October). $\quad$ Elevated carbon dioxide is predicted to promote coexistence among competing species in a trait-based model. Ecology and Evolution, 5(20), 47174733. doi: $10.1002 /$ ece3.1733

Anderegg, L. D., Berner, L. T., Badgley, G., Sethi, M. L., Law, B. E., \& HilleRisLambers, J. (2018). Within-species patterns challenge our understanding of the leaf economics spectrum. Ecology Letters, 21(5), 734-744. doi: $10.1111 /$ ele. 12945

Ball, J. T., Woodrow, I. E., \& Berry, J. A. (1987, January). A model predicting stomatal conductance and its contribution to the control of photosynthesis under different environmental conditions. Progress in Photosynthesis esearch, 4, 221-224. doi: 10.1007/978-94-017-0519-6_48

Bonan, G. B. (2008, June). Forests and climate change: forcings, feedbacks, and the climate benefits of forests. Science, 320, 1444-1449. doi: 10.1126/science .1155121

Bonan, G. B., Lawrence, P. J., Oleson, K. W., Levis, S., Jung, M., Reichstein, M., ... Swenson, S. C. (2011, May). Improving canopy processes in the Community Land Model version 4 (CLM4) using global flux fields empirically inferred from FLUXNET data. Journal of Geophysical Research, $116(\mathrm{G} 2), \mathrm{G} 02014$. doi: 10.1029/2010JG001593

Brienen, R. J. W., Phillips, O. L., Feldpausch, T. R., Gloor, E., BAKER, T. R., Lloyd, J., ... Zagt, R. J. (2015). Long-term decline of the Amazon carbon sink. Nature, $519(7543), 344-+$. doi: 10.1038/nature14283

Caldararu, S., Thum, T., Yu, L., \& Zaehle, S. $\quad$ (2020, 2020/08/27). Whole-plant optimality predicts changes in leaf nitrogen under variable co2 and nutrient availability. New Phytologist, 225(6), 2331-2346. doi: 10.1111/nph.16327

Cernusak, L. A., Haverd, V., Brendel, O., Le Thiec, D., Guehl, J.-M., \& Cuntz, M. (2019). Robust response of terrestrial plants to rising co2. Trends in plant science, 24(7), 578-586.

Cernusak, L. A., Winter, K., Dalling, J. W., Holtum, J. A. M., Jaramillo, C., Koerner, C., ... Wright, S. J. (2013). Tropical forest responses to increasing atmospheric CO2: current knowledge and opportunities for future research. Functional Plant Biology, 40(6), 531-551. doi: 10.1071/FP12309

Ciais, P., Sabine, C., Bala, G., Bopp, L., Brovkin, V., Canadell, J., .. . others (2013). Carbon and Other Biogeochemical Cycles. In Climate change 2013: the physical science basis. contribution of working group $i$ to the fifth assessment report of the intergovernmental panel on climate change (pp. 465-570). Cambridge University Press.

Cox, P. M., Betts, R. A., Jones, C. D., Spall, S. A., \& Totterdell, I. J. (2000). Acceleration of global warming due to carbon-cycle feedbacks in a coupled climate model (vol 408, pg 184, 2000). Nature, 408(6813), 750-750.

Cusack, D. F., Karpman, J., Ashdown, D., Cao, Q., Ciochina, M., Halterman, S., ... Neupane, A. (2016). Global change effects on humid tropical forests: Evidence for biogeochemical and biodiversity shifts at an ecosystem scale. Reviews of Geophysics, 54(3), 523-610.

Davies-Barnard, T., Meyerholt, J., Zaehle, S., Friedlingstein, P., Brovkin, V., Fan, Y., .. Wiltshire, A. (2020). Nitrogen cycling in cmip6 land surface mod- 
els: Progress and limitations. Biogeosciences Discussions, 2020, 1-32. doi: $10.5194 /$ bg-2019-513

Davin, E. L., \& de Noblet-Ducoudré, N. (2010, January). Climatic Impact of GlobalScale Deforestation: Radiative versus Nonradiative Processes. Journal of Climate, 23(1), 97-112. doi: 10.1175/2009JCLI3102.1

De Graaff, M.-A., Van Groenigen, K.-J., Six, J., Hungate, B., \& Van Kessel, C. $(2006,2020 / 08 / 04)$. Interactions between plant growth and soil nutrient cycling under elevated co2: a meta-analysis. Global Change Biology, 12(11), 2077-2091. doi: 10.1111/j.1365-2486.2006.01240.x

De Kauwe, M. G., Medlyn, B. E., Zaehle, S., Walker, A. P., Dietze, M. C., Hickler, T., ... Norby, R. J. (2013, March). Forest water use and water use efficiency at elevated $\mathrm{CO}_{2}$ : a model-data intercomparison at two contrasting temperate forest FACE sites. Global Change Biology, 19(6), 1759-1779. doi: $10.1111 / \mathrm{gcb} .12164$

De Kauwe, M. G., Medlyn, B. E., Zaehle, S., Walker, A. P., Dietze, M. C., Wang, Y.-P., ... Norby, R. J. (2014, May). Where does the carbon go? A modeldata intercomparison of vegetation carbon allocation and turnover processes at two temperate forest free-air $\mathrm{CO}_{2}$ enrichment sites. New Phytologist, 203(3), 883-899. doi: $10.1111 /$ nph. 12847

Deutsch, C. A., Tewksbury, J. J., Tigchelaar, M., Battisti, D. S., Merrill, S. C., Huey, R. B., \& Naylor, R. L. (2018). Increase in crop losses to insect pests in a warming climate. Science, 361(6405), 916-919.

Dewar, R. C., Tarvainen, L., Parker, K., Wallin, G., \& McMurtrie, R. E. $\quad$ (2012). Why does leaf nitrogen decline within tree canopies less rapidly than light? an explanation from optimization subject to a lower bound on leaf mass per area. Tree Physiology, 32(5), 520-534.

Doughty, C. E., Santos-Andrade, P. E., Shenkin, A., Goldsmith, G. R., Bentley, L. P., Blonder, B., ... others (2018). Tropical forest leaves may darken in response to climate change. Nature ecology \& evolution, 2(12), 1918-1924.

Drake, B. G., \& Gonzàlez-Meler, M. A. (1997). More efficient plants: a consequence of rising atmospheric CO2? Annual Review of Plant Physiology, 48(1), 609639. doi: 10.1146/annurev.arplant.48.1.609

Falster, D. S., Brännström, Å., Westoby, M., \& Dieckmann, U. (2017). Multitrait successional forest dynamics enable diverse competitive coexistence. Proceedings of the National Academy of Sciences, 114(13), E2719-E2728.

Faybishenko, B., Paton, S., Powell, T., Knox, R., Pastorello, G., Varadharajan, C., ... Agarwal, D. (2018). QA/QC-ed BCI meteorological drivers (Tech. Rep.). United States. doi: doi:10.15486/ngt/1423307

Fisher, R. A., \& Koven, C. D. $\quad(2020,2020 / 05 / 12)$. Perspectives on the future of land surface models and the challenges of representing complex terrestrial systems. Journal of Advances in Modeling Earth Systems, 12(4), e2018MS001453. doi: 10.1029/2018MS001453

Fisher, R. A., Koven, C. D., Anderegg, W. R., Christoffersen, B. O., Dietze, M. C., Farrior, C. E., ... others (2018). Vegetation demographics in Earth System Models: A review of progress and priorities. Global Change Biology, 24(1), $35-54$.

Fisher, R. A., McDowell, N., Purves, D., Moorcroft, P., Sitch, S., Cox, P., ... Ian Woodward, F. (2010). Assessing uncertainties in a second-generation dynamic vegetation model caused by ecological scale limitations. New Phytologist, 187(3), 666-681.

Fisher, R. A., Muszala, S., Verteinstein, M., Lawrence, P., Xu, C., McDowell, N. G., ... Bonan, G. (2015). Taking off the training wheels: the properties of a dynamic vegetation model without climate envelopes. Geoscientific Model Development Discussions, 8(4), 3293-3357. doi: 10.5194/gmdd-8-3293-2015

Fisher, R. A., Wieder, W. R., Sanderson, B. M., Koven, C. D., Oleson, K. W., Xu, 
C., ... Lawrence, D. M. (2019). Parametric controls on vegetation responses to biogeochemical forcing in the clm5. Journal of Advances in Modeling Earth Systems, 11(9), 2879-2895.

Fleischer, K., Rammig, A., De Kauwe, M. G., Walker, A. P., Domingues, T. F., Fuchslueger, L., ... others (2019). Amazon forest response to co 2 fertilization dependent on plant phosphorus acquisition. Nature Geoscience, 12(9), 736-741.

Fyllas, N. M., Patiño, S., Baker, T. R., Bielefeld Nardoto, G., Martinelli, L. A., Quesada, C. A., ... Lloyd, J. (2009). Basin-wide variations in foliar properties of amazonian forest: phylogeny, soils and climate. Biogeosciences, 6(11), 2677-2708. doi: 10.5194/bg-6-2677-2009

Garbutt, K., Williams, W. E., \& Bazzaz, F. A. $\quad$ (1990, 2020/07/17). Analysis of the differential response of five annuals to elevated co2 during growth. Ecology, 71 (3), 1185-1194. doi: 10.2307/1937386

Geange, S. R., Briceño, V. F., Aitken, N. C., Ramirez-Valiente, J. A., HollowayPhillips, M.-M., \& Nicotra, A. B. (2017). Phenotypic plasticity and water availability: responses of alpine herb species along an elevation gradient. $\quad C l i-$ mate Change Responses, 4(1), 5.

Ghimire, B., Riley, W. J., Koven, C. D., Mu, M., \& Randerson, J. T. (2016, March). Representing leaf and root physiological traits in CLM improves global carbon and nitrogen cycling predictions. Journal of Advances in Modeling Earth Systems. doi: 10.1002/2015MS000538

Hickler, T., Smith, B., Prentice, I. C., Mjöfors, K., Miller, P., Arneth, A., \& Sykes, M. T. (2008, July). CO 2fertilization in temperate FACE experiments not representative of boreal and tropical forests. Global Change Biology, 14(7), 1531-1542. doi: 10.1111/j.1365-2486.2008.01598.x

Holm, J. A., Knox, R. G., Zhu, Q., Fisher, R. A., Koven, C. D., Nogueira Lima, A. J., ... others (2020). The central amazon biomass sink under current and future atmospheric co2: Predictions from big-leaf and demographic vegetation models. Journal of Geophysical Research: Biogeosciences, 125(3), e2019JG005500.

Hungate, B. A., Dukes, J. S., Shaw, M. R., Luo, Y., \& Field, C. B. $\quad$ (2003, November). Nitrogen and climate change. Science, 302, 1512-1513. doi: 10.1126/ science. 1091390

Ishizaki, S., Hikosaka, K., \& Hirose, T. (2003). Increase in leaf mass per area benefits plant growth at elevated $\mathrm{CO}_{2}$ concentration. Annals of Botany, 91(7), 905-914. doi: 10.1093/aob/mcg097

Kattge, J., Diaz, S., Lavorel, S., Prentice, I. C., Leadley, P., Bonisch, G., ... al, e. (2011). TRY-a global database of plant traits . Global Change Biology, 17, 2905-2935. doi: 10.1111/j.1365-2486.2011.02451.x

Kattge, J., Knorr, W., Raddatz, T., \& Wirth, C. (2009, April). Quantifying photosynthetic capacity and its relationship to leaf nitrogen content for global-scale terrestrial biosphere models. Global Change Biology, 15(4), 976-991. doi: 10.1111/j.1365-2486.2008.01744.x

Körner, C., \& Arnone, J. A. (1992). Responses to elevated carbon dioxide in artificial tropical ecosystems. Science, 257(5077), 1672-1675.

Koven, C. D., Knox, R. G., Fisher, R. A., Chambers, J. Q., Christoffersen, B. O., Davies, S. J., ... Xu, C. (2020). Benchmarking and parameter sensitivity of physiological and vegetation dynamics using the functionally assembled terrestrial ecosystem simulator (fates) at barro colorado island, panama. Biogeosciences, 17(11), 3017-3044. doi: 10.5194/bg-17-3017-2020

Kovenock, M. (2019). Ecosystem and large-scale climate impacts of plant leaf dynamics (Unpublished doctoral dissertation). University of Washington.

Kovenock, M., \& Swann, A. L. S. (2018, October). Leaf Trait Acclimation Amplifies Simulated Climate Warming in Response to Elevated Carbon Dioxide. Global 
Biogeochemical Cycles, 32. doi: 10.1029/2018GB005883

Lawrence, D., Fisher, R. A., Koven, C. D., Oleson, K. W., Swenson, S. C., Vertenstein, M., ... Xu, C. (2018, May). Technical Description of version 5.0 of the Community Land Model (CLM).

Leakey, A. D. B., Ainsworth, E. A., Bernacchi, C. J., Zhu, X., Long, S. P., \& Ort, D. R. (2012). Photosynthesis in a $\mathrm{CO}_{2}$-Rich Atmosphere. In Photosynthesis in silico (pp. 733-768). Dordrecht: Springer Netherlands. doi: 10.1007/978-94-007-1579-0_29

Leakey, A. D. B., Bishop, K. A., \& Ainsworth, E. A. (2012, June). A multi-biome gap in understanding of crop and ecosystem responses to elevated CO2. Current Opinion in Plant Biology, 15(3), 228-236. doi: 10.1016/j.pbi.2012.01.009

Lloyd, J., \& Farquhar, G. D. (2008, May). Effects of rising temperatures and $\left[\mathrm{CO}_{2}\right]$ on the physiology of tropical forest trees. Philosophical Transactions of the Royal Society B: Biological Sciences, 363(1498), 1811-1817. doi: 10.1098/rstb.2007.0032

Lloyd, J., Patiño, S., Paiva, R. Q., Quesada, C. A. N., Nardoto, G. B., Santos, A. J. B., ... Mercado, L. M. (2010). Optimisation of photosynthetic carbon gain and within-canopy gradients of associated foliar traits for Amazon forest trees. Biogeosciences, 7(6), 1833-1859. doi: 10.5194/bg-7-1833-2010

Lovelock, C. E., Winter, K., Mersits, R., \& Popp, M. (1998). Responses of communities of tropical tree species to elevated $\mathrm{CO}_{2}$ in a forest clearing. Oecologia, 116(1), 207-218.

Luo, Y., Field, C. B., \& Mooney, H. A. (1994, November). Predicting responses of photosynthesis and root fraction to elevated $\left[\mathrm{CO}_{2}\right]$ a: interactions among carbon, nitrogen, and growth. Plant, Cell and Environment, 17(11), 1195-1204. doi: $10.1111 /$ j.1365-3040.1994.tb02017.x

Luo, Y., Hui, D., \& Zhang, D. (2006, January). Elevated $\mathrm{CO}_{2}$ stimulates net accumulations of carbon and nitrogen in land ecosystems: A meta-analysis. Ecology, 87(1), 53-63.

Luo, Y., Su, B., Currie, W. S., Dukes, J. S., Finzi, A. C., Hartwig, U., .. Field, C. B. (2004, August). Progressive nitrogen limitation of ecosystem responses to rising atmospheric carbon dioxide. BioScience, 54 (8), 731-739. doi: 10.1641/0006-3568(2004)054[0731:PNLOER]2.0.CO;2

Lusk, C. H., Reich, P. B., Montgomery, R. A., Ackerly, D. D., \& Cavender-Bares, J. (2008). Why are evergreen leaves so contrary about shade? Trends in Ecology E3 Evolution, 23(6), 299-303. doi: 10.1016/j.tree.2008.02.006

Mahowald, N., Lo, F., Zheng, Y., Harrison, L., Funk, C., Lombardozzi, D., \& Goodale, C. (2016). Projections of leaf area index in earth system models. Earth System Dynamics, 7(1), 211-229. doi: 10.5194/esd-7-211-2016

Massoud, E. C., Xu, C., Fisher, R. A., Knox, R. G., Walker, A. P., Serbin, S. P., ... others (2019). Identification of key parameters controlling demographically structured vegetation dynamics in a land surface model: Clm4. 5 (fates). Geoscientific Model Development, 12(9), 4133-4164.

McMurtrie, R. E., \& Dewar, R. C. (2011). Leaf-trait variation explained by the hypothesis that plants maximize their canopy carbon export over the lifespan of leaves. Tree physiology, 31(9), 1007-1023.

McMurtrie, R. E., Norby, R. J., Medlyn, B. E., Dewar, R. C., Pepper, D. A., Reich, P. B., \& Barton, C. V. (2008). Why is plant-growth response to elevated CO2 amplified when water is limiting, but reduced when nitrogen is limiting? A growth-optimisation hypothesis. Functional Plant Biology, 35(6), 521-534.

Medlyn, B. E., Duursma, R. A., Eamus, D., Ellsworth, D. S., Prentice, I. C., Barton, C. V. M., ... Wingate, L. (2011, January). Reconciling the optimal and empirical approaches to modelling stomatal conductance. Global Change Biology, 17(6), 2134-2144. doi: 10.1111/j.1365-2486.2010.02375.x

Medlyn, B. E., Zaehle, S., De Kauwe, M. G., Walker, A. P., Dietze, M. C., Han- 
son, P. J., ... Norby, R. J. improve vegetation models. $10.1038 /$ nclimate2621

Meyerholt, J., \& Zaehle, S. $\quad$ (2015, July). The role of stoichiometric flexibility in modelling forest ecosystem responses to nitrogen fertilization. New Phytologist, 208(4), 1042-1055. doi: 10.1111/nph.13547

Moorcroft, P. R., Hurtt, G. C., \& Pacala, S. W. (2001). A method for scaling vegetation dynamics: the ecosystem demography model (ED). Ecological monographs, 71, 557-586.

Norby, R. J., De Kauwe, M. G., \& Domingues, T. F. (2016). Model-data synthesis for the next generation of forest free-air $\mathrm{CO}_{2}$ enrichment (FACE) experiments. New Phytologist, 209, 17-28.

Norby, R. J., Gu, L., Haworth, I. C., Jensen, A. M., Turner, B. L., Walker, A. P., ... Winter, K. (2017). Informing models through empirical relationships between foliar phosphorus, nitrogen and photosynthesis across diverse woody species in tropical forests of panama. New Phytologist, 215(4), 1425-1437.

Norby, R. J., Sholtis, J. D., Gunderson, C. A., \& Jawdy, S. S. (2003, August). Leaf dynamics of a deciduous forest canopy: no response to elevated $\mathrm{CO}_{2}$. Oecologia, 136(4), 574-584. doi: 10.1007/s00442-003-1296-2

Norby, R. J., Warren, J. M., Iversen, C. M., Medlyn, B. E., \& McMurtrie, R. E. (2010). $\quad \mathrm{CO}_{2}$ enhancement of forest productivity constrained by limited nitrogen availability. Proceedings of the National Academy of Sciences of the United States of America, 107(45), 19368-19373. doi: 10.1073/pnas.1006463107

Poorter, H., Berkel, Y. v., Baxter, R., Hertog, J. d., Dijkstra, P., Gifford, R. M., ... Wong, S. C. (1997). The effect of elevated $\mathrm{CO}_{2}$ on the chemical composition and construction costs of leaves of $27 \mathrm{C}_{3}$ species. Plant, Cell and Environment, 20(4), 472-482. doi: 10.1046/j.1365-3040.1997.d01-84.x

Poorter, H., Niinemets, Ü., Poorter, L., Wright, I. J., \& Villar, R. （2009, May). Causes and consequences of variation in leaf mass per area (LMA): a metaanalysis. New Phytologist, 182, 565-588. doi: 10.1111/j.1469-8137.2009.02830 . $\mathrm{x}$

Power, S. C., Verboom, G. A., Bond, W. J., \& Cramer, M. D. (2019). Does a tradeoff between trait plasticity and resource conservatism contribute to the maintenance of alternative stable states? New Phytologist, 223(4), 1809-1819.

Prentice, I. C., Dong, N., Gleason, S. M., Maire, V., \& Wright, I. J. (2014). Balancing the costs of carbon gain and water transport: testing a new theoretical framework for plant functional ecology. Ecology letters, 17(1), 82-91.

Pritchard, S. H., Rogers, H. O., Prior, S. A., \& Peterson, C. M. （1999). Elevated $\mathrm{CO}_{2}$ and plant structure: a review. Global Change Biology, 5(7), 807-837. doi: 10.1046/j.1365-2486.1999.00268.x

Purves, D. W., Lichstein, J. W., Strigul, N., \& Pacala, S. W. (2008). Predicting and understanding forest dynamics using a simple tractable model. Proceedings of the National Academy of Sciences, 105(44), 17018-17022.

Quebbeman, J., \& Ramirez, J. (2016). Optimal allocation of leaf-level nitrogen: Implications for covariation of vcmax and jmax and photosynthetic downregulation. Journal of Geophysical Research: Biogeosciences, 121(9), 2464-2475.

Reekie, E. G., \& Bazzaz, F. A. (1989, January). Competition and patterns of resource use among seedlings of five tropical trees grown at ambient and elevated $\mathrm{CO}_{2}$. Oecologia, $79(2), 212-222$. doi: $10.2307 / 4218947$ ?ref=no-X-route: 40f91c19f6c4e030b308b9050ce77413

Rogers, A., Medlyn, B. E., Dukes, J. S., Bonan, G., von Caemmerer, S., Dietze, M. C., ... Zaehle, S. (2017, January). A roadmap for improving the representation of photosynthesis in Earth system models. The New phytologist, 213(1), 22-42. doi: 10.1111/nph.14283

Roumet, C., Laurent, G., \& Roy, J. (1999). Leaf structure and chemical composition 
as affected by elevated $\mathrm{CO}_{2}$ : genotypic responses of two perennial grasses. New Phytologist, 143(1), 73-81. doi: 10.1046/j.1469-8137.1999.00437.x

Schimel, D., Stephens, B. B., \& Fisher, J. B. (2015, January). Effect of increasing $\mathrm{CO}_{2}$ on the terrestrial carbon cycle. Proceedings of the National Academy of Sciences of the United States of America, 112(2), 436-441. doi: 10.1073/pnas .1407302112

Smith, N. G., Keenan, T. F., Colin Prentice, I., Wang, H., Wright, I. J., Niinemets, Ü., ... others (2019). Global photosynthetic capacity is optimized to the environment. Ecology letters, 22(3), 506-517.

Sterck, F., Markesteijn, L., Schieving, F., \& Poorter, L. (2011). Functional traits determine trade-offs and niches in a tropical forest community. Proceedings of the National Academy of Sciences, 108(51), 20627-20632.

Swann, A. L. S., Hoffman, F. M., Koven, C. D., \& Randerson, J. T. September). Plant responses to increasing $\mathrm{CO}_{2}$ reduce estimates of climate impacts on drought severity. Proceedings of the National Academy of Sciences of the United States of America, 113(36), 10019-10024. doi: $10.1073 /$ pnas. 1604581113

Taylor, G., Tallis, M. J., Giardina, C. P., Percy, K. E., Miglietta, F., Gupta, P. S., ... Karnosky, D. F. (2008). Future atmospheric $\mathrm{CO}_{2}$ leads to delayed autumnal senescence. Global Change Biology, 14(2), 264-275. doi: $10.1111 / \mathrm{j} .1365-2486.2007 .01473 . x$

Thomas, R. Q., \& Williams, M. (2014). A model using marginal efficiency of investment to analyze carbon and nitrogen interactions in terrestrial ecosystems (aconite version 1). Geoscientific Model Development, 7(5), 2015-2037.

Tully, K., \& Lawrence, D. (2010). Declines in leaf litter nitrogen linked to rising temperatures in a wet tropical forest. Biotropica, 526-530.

van der Sleen, P., Groenendijk, P., Vlam, M., Anten, N. P. R., Boom, A., Bongers, F., ... Zuidema, P. A. (2015, January). No growth stimulation of tropical trees by 150 years of $\mathrm{CO}_{2}$ fertilization but water-use efficiency increased. Nature, 8(1), 24-28. doi: 10.1038/ngeo2313

Verheijen, L. M., Aerts, R., Brovkin, V., Cavender-Bares, J., Cornelissen, J. H. C., Kattge, J., \& van Bodegom, P. M. (2015, March). Inclusion of ecologically based trait variation in plant functional types reduces the projected land carbon sink in an earth system model. Global Change Biology, 21 (8), 3074-3086. doi: $10.1111 /$ gcb.12871

Verheijen, L. M., Brovkin, V., Aerts, R., Bonisch, G., Cornelissen, J. H. C., Kattge, J., .. Van Bodegom, P. M. (2013). Impacts of trait variation through observed trait-climate relationships on performance of an Earth system model: a conceptual analysis. Biogeosciences, 10(8), 5497-5515. doi: 10.5194/bg-10-5497-2013

Walker, A. P., Beckerman, A. P., Gu, L., Kattge, J., Cernusak, L. A., Domingues, T. F., ... Woodward, F. I. (2014). The relationship of leaf photosynthetic traits-Vcmax and Jmax-to leaf nitrogen, leaf phosphorus, and specific leaf area: a meta-analysis and modeling study. Ecology and Evolution, 4(16), $3218-3235$.

Walker, A. P., Quaife, T., van Bodegom, P. M., De Kauwe, M. G., Keenan, T. F., Joiner, J., ... others (2017). The impact of alternative trait-scaling hypotheses for the maximum photosynthetic carboxylation rate (vcmax) on global gross primary production. New Phytologist, 215(4), 1370-1386.

Weng, E., Malyshev, S., Lichstein, J., Farrior, C., Dybzinski, R., Zhang, T., ... Pacala, S. W. (2015). Scaling from individual trees to forests in an earth system modeling framework using a mathematically tractable model of heightstructured competition. Biogeosciences.

Winter, K., Garcia, M., Gottsberger, R., \& Popp, M. (2001). Marked growth response of communities of two tropical tree species to elevated co2 when soil 
nutrient limitation is removed. Flora, 196(1), 47-58.

Winter, K., Garcia, M., Lovelock, C. E., Gottsberger, R., \& Popp, M. Responses of model communities of two tropical tree species to elevated atmospheric CO 2: growth on unfertilized soil. Flora, 195(4), 289-302.

Winter, K., \& Lovelock, C. E. (1999). Growth responses of seedlings of early and late successional tropical forest trees to elevated atmospheric $\mathrm{CO}_{2}$. Flora, 194 (2), 221-227.

Wright, I. J., Reich, P. B., Westoby, M., Ackerly, D. D., Baruch, Z., Bongers, F., ... Villar, R. (2004). The worldwide leaf economics spectrum. Nature, 428(6985), 821-827. doi: 10.1038/nature02403

Xu, C., Fisher, R., Wullschleger, S. D., Wilson, C. J., Cai, M., \& McDowell, N. G. (2012). Toward a mechanistic modeling of nitrogen limitation on vegetation dynamics. PloS one, 7(5), e37914.

Yin, X. (2002). Responses of leaf nitrogen concentration and specific leaf area to atmospheric $\mathrm{CO} 2$ enrichment: a retrospective synthesis across 62 species. Global Change Biology, 8(7), 631-642.

Zaehle, S., \& Friend, A. D. (2010, February). Carbon and nitrogen cycle dynamics in the O-CN land surface model: 1. Model description, site-scale evaluation, and sensitivity to parameter estimates. Global Biogeochemical Cycles, 24(1). doi: 10.1029/2009GB003521

Zaehle, S., Medlyn, B. E., De Kauwe, M. G., Walker, A. P., Dietze, M. C., Hickler, T., ... Norby, R. J. (2014, January). Evaluation of 11 terrestrial carbon-nitrogen cycle models against observations from two temperate Free-Air $\mathrm{CO}_{2}$ Enrichment studies. $\quad$ New Phytologist, 202(3), 803-822. doi: $10.1111 / \mathrm{nph} .12697$

Zhang, K., Kimball, J. S., Nemani, R. R., Running, S. W., Hong, Y., Gourley, J. J., \& Yu, Z. (2015, October). Vegetation Greening and Climate Change Promote Multidecadal Rises of Global Land Evapotranspiration. Nature Publishing Group, 1-9. doi: 10.1038/srep15956

Zhu, Z., Piao, S., Myneni, R. B., Huang, M., Zeng, Z., Canadell, J. G., ... Zeng, N. (2016, April). Greening of the Earth and its drivers. Nature Climate Change. doi: $10.1038 /$ nclimate3004 